\title{
A PEGADA HÍDRICA DA ECONOMIA BRASILEIRA E A BALANÇA COMERCIAL DE ÁGUA VIRTUAL: UMA ANÁLISE INSUMO-PRODUTO
}

\author{
Marco Antonio Montoya *
}

\begin{abstract}
Resumo
O artigo avalia, com base na construção de um modelo insumo-produto ecológico, a pegada hídrica nacional e a balança comercial de água virtual no Brasil para o ano 2015. Verificou-se que a pegada hídrica do país alcança $22.012 \mathrm{hm}^{3}$ /ano de água virtual, o que equivale a um consumo per-capita de 107,66 m³/ano ou 294,97 litros/dia. Na balança comercial, verificou-se, em função dos setores da agropecuária e da agroindústria, um saldo exportador líquido de $8.542 \mathrm{hm}^{3} /$ ano de água virtual que abastece a cada ano 79,33 milhões de habitantes no mundo. Contudo, frente à escassez de água global, para proteger o meio ambiente de forma sustentável, é necessário criar um mercado formal de água virtual.
\end{abstract}

Palavras-chave: insumo-produto, pegada hídrica, produção setorial, meio ambiente.

\begin{abstract}
The article evaluates, based on the construction of an ecological inputoutput model, the national water footprint and the virtual commercial water balance in Brazil for 2015. It was found that the country's water footprint reaches $22,012 \mathrm{hm}^{3}$ /year of water virtual, which is equivalent to a per capita consumption of $107.66 \mathrm{~m}^{3} /$ year or 294.97 liters/day. In the trade balance, there was a net export balance of $8,542 \mathrm{hm}^{3} /$ year of virtual water, which supplies 79.33 million inhabitants worldwide each year, depending on the agricultural and agribusiness sectors. However, in the face of global water scarcity, in order to protect the environment in a sustainable way, it is necessary to create a formal virtual water market.
\end{abstract}

Keywords: input-output, water footprint, sectoral production, environment.

JEL classification: C67, Q25, E23, Q50.

DOI: ht tp://dx.doi .org/10.11606/1980-5330/ea167721

\footnotetext{
* Doutor em Economia Aplicada. Professor Titular da Universidade de Passo Fundo (UPF). E-mail: montoya@upf.br, https://orcid.org/0000-0003-1566-7417. Universidade de Passo Fundo, Faculdade de Ciência Econômicas Administrativas e Contábeis (UPF/FEAC), Campus I. BR 285, Km 292,7, Bairro São José, Passo Fundo, RS, CEP 99052-900, Brasil.
} 


\section{Introdução}

O Brasil, ao longo dos últimos 50 anos, vem pressionando o meio ambiente por maiores recursos hídricos devido ao crescimento econômico, que lhe deu o status da oitava economia mundial, bem como ao aumento da população que duplicou, passando de 93,1 milhões em 1970 para 201,1 milhões de habitantes em 2020.

Embora a água seja um recurso abundante no país, já que possui as maiores reservas de água doce (12\%) do planeta, na economia brasileira, ela é tratada como um recurso escasso. Para entender o problema, é preciso considerar que essas reservas estão desigualmente distribuídas geográfica e demograficamente. Enquanto a região Norte apresenta a maior concentração de água em virtude da localização da Bacia do Rio Amazonas e o Aquífero Alter do Chão, a grande parte da população brasileira concentra-se nas regiões Sudeste e Nordeste, que, historicamente, sofrem de secas e escassez de água (PENA 2018).

Para atender à crescente demanda de água e corrigir a distribuição natural das chuvas e dos rios, diversas obras de engenharia foram implementadas no país. Ao longo do território, destacam-se a construção de reservatórios artificiais; a integração do rio São Francisco com as bacias hidrográficas do nordeste setentrional, por meio de sua transposição; a promoção de projetos de irrigação para o uso de pivôs centrais, que, segundo a EMBRAPA. Empresa Brasileira de Pesquisa Agropecuária (2016), irrigam uma área de 1,275 milhão de hectares e coloca o Brasil entre os dez países com maior área irrigada no planeta.

Nesse panorama que intensifica a necessidade cada vez maior de recursos hídricos para atender ao crescimento econômico e populacional brasileiro, questiona-se: Quanta água é consumida na produção de bens e serviços finais do país? Responder a essa pergunta não é trivial, já que o consumo ocorre de duas maneiras: de forma direta, quando alguém abre a torneira para realizar atividades cotidianas domésticas; e de forma indireta, por intermédio da aquisição de bens de consumo, como carros, roupas, material de limpeza, produtos alimentícios, etc. O problema do consumo indireto de água é que ela passa despercebida pelas pessoas por ser "invisível"; assim, ignoram-se as enormes quantidades de água embutidas nos processos de produção de bens e serviços finais consumidos no país. Para avaliar a quantidade de água consumida no sistema econômico é necessária, portanto, uma categoria de análise que integre o consumo direto e indireto de água, tal como o faz a Pegada Hídrica Nacional ao mensurar a água virtual, em outras palavras, o consumo de água incorporada ao longo dos processos de produção dos bens e serviços finais.

Deve-se levar em conta também que o Brasil, no mercado internacional, é considerado como um grande fornecedor de alimentos; assim, em função do consumo indireto de água na produção, pode-se inferir que, por meio de suas exportações, também é um grande fornecedor de água para a economia mundial. Fato que também deve ser avaliado na balança comercial para ter a verdadeira dimensão do consumo de água no país.

Nesse contexto e no âmbito da contabilidade ambiental, este artigo tem como objetivo mensurar, na estrutura da economia brasileira, a pegada hídrica nacional, com fins de estabelecer a quantidade de água incorporada ou consumida na produção de bens e serviços finais, bem como avaliar, no mercado internacional, o saldo da balança comercial de água virtual do país. Com 
esses fins, utiliza-se um modelo insumo-produto ecológico que incorpora o consumo setorial de água para o ano de 2015. Espera-se, com esta pesquisa, em um primeiro momento, compreender melhor as interações das atividades econômicas do país com os fluxos de água, gerar informações acerca da inserção internacional do Brasil na escassez global de água, bem como fornecer indicadores para um melhor planejamento dos recursos hídricos nos próximos anos.

Após esta introdução, o presente artigo está dividido da seguinte maneira: na seção 2, é feita uma breve discussão sobre a noção conceitual da pegada hídrica nacional e os enfoques metodológicos adotados para sua avaliação; na seção 3, apresentam-se a estrutura matemática do método de mensuração da pegada hídrica bem como a base de dados utilizada; na seção 4, avaliamse o consumo setorial de água no país e a água embutida nos produtos do país denominada como água virtual; na seção 5 , investigam-se, na estrutura da economia brasileira, a dimensão da pegada hídrica nacional e a balança comercial da água virtual; na última seção, são apresentadas as principais conclusões obtidas no decorrer da análise.

\section{Revisão bibliográfica}

A seguir, são apresentadas noções conceituais sobre a pegada hídrica nacional e a abrangência dos enfoques metodológicos que mensuram a água virtual. Para isso, apresentam-se alguns aspectos inerentes à diferença entre o uso e o consumo de água, a pegada hídrica como categoria de análise ambiental, bem como a abrangência dos modelos insumo-produto ecológicos para avaliar a água virtual incorporada nos bens e nos serviços finais do país.

\subsection{Diferença substancial entre o uso e o consumo de água}

Nas atividades econômicas, os recursos hídricos contribuem permanentemente com o crescimento econômico do país, na medida em que a água é utilizada para o consumo humano e animal, produção de alimentos, como insumo de processos produtivos da indústria, bem como é usada na geração de energia elétrica, navegação, lazer, ou como local para descarte e diluição de afluentes domésticos e industriais. No sistema econômico, segundo a Agência Nacional de Águas - ANA. Agência Nacional de Águas (2018), o uso total da água considera toda a água retirada do meio ambiente e das atividades econômicas para ser utilizada pelos setores produtivos e pelas famílias. Já o consumo total de água constitui a parcela da água retirada para uso que não retorna ao ambiente, pois, durante o uso, foi incorporada nos produtos e consumida pelas famílias ou rebanhos.

Nesse contexto, com base no Anexo Apêndice A, observa-se que o uso total de água na economia brasileira alcança $3.219 .507 \mathrm{hm}^{3}$ ao ano. Esse volume representa o total de água retirada do meio ambiente $\left(3.201 .731 \mathrm{hm}^{3}\right)$, mais as águas que são provenientes de outras atividades econômicas $\left(17.775 \mathrm{hm}^{3}\right)$. Chama atenção que, do total de água utilizada no país, em sua grande maioria, $3.188 .907 \mathrm{hm}^{3}$, ou $99,05 \%$, retornou ao meio ambiente $\left(3.171 .131 \mathrm{hm}^{3}\right)$ e às próprias atividades produtivas $\left(17.776 \mathrm{hm}^{3}\right)$; e apenas $30.600 \mathrm{hm}^{3}$, ou $0,95 \%$, foram consumidas pelas atividades econômicas $\left(30.554 \mathrm{hm}^{3}\right)$ e pelas famílias $\left(46 \mathrm{hm}^{3}\right)$. A esse respeito, cabe salientar que, na literatura internacional e em 
sites de informação, confunde-se o uso da água com o consumo de água, o que superestima a real dimensão do consumo per-capita de água nos países.

\subsection{Pegada hídrica nacional e água virtual}

Em analogia à pegada ecológica, como medida da apropriação humana das áreas biologicamente produtivas, HOEKSTRA \& HUNG (2002) introduziram o conceito de pegada hídrica nacional (PHN) como um indicador do volume total de água doce consumida ou incorporada no processo de produção de bens e serviços finais de um país. Note-se que, devido à inerente interdependência setorial do sistema econômico, ao calcular nos processos produtivos o volume de água que é incorporada ou embutida nos produtos e nos serviços finais, a pegada hídrica leva em consideração os impactos diretos e indiretos do consumo de água no meio ambiente. Em virtude disso, a pegada hídrica de um indivíduo, família, comunidade ou país pode ser estimada multiplicandose todos os bens e serviços finais consumidos por seus respectivos volumes de água incorporados ou consumidos.

Considerando que muitos dos produtos finais são consumidos no mercado doméstico e outros no mercado internacional, ALLAN (1998), ao avaliar as commodities agrícolas, introduz o conceito de água virtual como o volume de água incorporada nos produtos comercializados no mercado internacional. Ele se refere à apropriação dos recursos hídricos de outros países no processo de exportação e importação de bens e serviços (CHAPAGAIN \& HOEKSTRA 2007, OEL \& HOEKSTRA 2012).

Em função dessa definição conceitual, ao estimar o volume de água incorporada, existe uma relação complementar entre a pegada hídrica e o conceito de água virtual, razão pela qual, na literatura, a pegada hídrica também é definida como o volume de "água virtual" ou "água incorporada" nos bens e serviços finais consumidos pelos indivíduos e pelas nações (ver HOEKSTRA (2009); BLENINGER \& KOTSUKA (2015)).

A pegada hídrica e a água virtual constituem, portanto, categorias de análise do desenvolvimento sustentável para avaliar a gestão dos recursos híbridos escassos, bem como sua desigual distribuição nos diversos segmentos territoriais do mundo. Assim, com a avaliação da pegada hídrica dos países, pretende-se descobrir como o planeta pode proporcionar água doce suficiente para assegurar o bem-estar das pessoas, considerando que a água doce é escassa e representa, segundo GLEICK (2000), apenas 2,5\% do volume total de recursos hídricos.

\section{Tipos de pegada hídrica}

A pegada hídrica total está composta pela somatória da pegada hídrica verde, azul e cinza. A pegada hídrica verde representa a água proveniente da chuva, que não é retirada nem armazenada pelos mananciais, mas sim armazenada temporariamente na superfície no solo úmido ou vegetação (HOEKSTRA 2009). Ela representa o volume de água da chuva consumida ou incorporada nos produtos durante o processo de produção. O cálculo da pegada hídrica verde é particularmente relevante para produtos agrícolas, devido à evapotranspiração, ou seja, a perda de água de um ecossistema para a atmosfera, causada pela evaporação a partir do solo e pela transpiração das plantas (WICHELNS 2010). 
A pegada hídrica azul está constituída pelas águas da superficiais (rios, córregos, reservatórios artificiais, lagos e geleiras) e subterrâneas (aquíferos) que são consumidas ou incorporadas no processo de produção de um bem (HOEKSTRA et al. 2011). Já a pegada hídrica cinza é aquela que se tornou poluída durante o processo produtivo, sendo definida como a quantidade de água necessária para diluir a carga de poluentes a níveis aceitáveis, estabelecidos nos padrões de qualidade e de potabilidade existentes. Ainda que a Água Cinza não represente necessariamente entrada de água no sistema, compõe a pegada hídrica por representar o volume de água que seria necessário para a neutralização total da carga ambiental enviada aos recursos hídricos (HOEKSTRA 2009).

Nesse contexto, cabe destacar que a pegada hídrica do ponto de vista ambiental considera que os impactos diretos se referem ao consumo da água em atividades cotidianas domésticas e que o impacto indireto refere-se ao consumo de água que está incorporado nos bens e serviços finais. Em virtude disso, pelo volume consumido de bens e serviços durante um ano, percebe-se que a pegada hídrica indireta é superior à pegada hídrica direta; apesar disso e por ser "invisível", ela é geralmente negligenciada.

\subsection{Enfoques metodológicos adotados para avaliar a pegada hídrica}

Atualmente, os diversos estudos que avaliam a pegada hídrica podem ser agrupados em duas categorias metodológicas: o método da árvore de produção e o método de insumo-produto ecológico.

O enfoque do método da árvore de produção é utilizado para calcular o teor de água virtual das culturas. Esse método geralmente combina com os dados climáticos locais. Quanto aos produtos de origem animal, esse método estima, em primeiro lugar, a água verde, a água azul e a água cinza contida na alimentação animal; e, em seguida, considera a escala ou o volume de produção para calcular o conteúdo específico de água virtual dos produtos animais. Para os produtos industriais, a maneira de calcular o teor de água virtual é semelhante ao dos produtos de origem animal, e o valor correspondente da pegada hídrica pode ser obtido pela multiplicação do teor de água virtual pelo volume de produção ou consumo de produtos (RODRIGUEZ et al. 2014, SU et al. 2015). Contudo, esse método apresenta limitações para calcular a água incorporada, principalmente nos produtos industrializados e serviços, na medida em que não leva em consideração todo o sistema econômico. Desse modo, negligencia a interdependência dos setores econômicos, não fornece a água virtual dos serviços nos fluxos do sistema econômico, bem como apresenta dupla contagem ao não considerar a água incorporada nos produtos importados que servem de insumos para as exportações do país.

Já o enfoque do método insumo-produto ecológico geralmente adota informações sobre os fluxos de água que interagem com as atividades econômicas. Os cálculos da água virtual e a pegada hídrica decorrem dos coeficientes de água direto e total do sistema econômico. Assim, a pegada hídrica pode ser derivada da multiplicação do coeficiente total de água pela demanda final do país ou região. Dessa forma, o consumo da água é captado de forma sistêmica no processo circular da economia (ZHAO et al. 2009, ZHANG et al. 2011). 
Abrangência analítica dos modelos insumo-produto no meio ambiente

A importância de avaliar a pegada hídrica está associada aos riscos e às incertezas ambientais decorrentes da escassez de água doce versus o crescente consumo de água no sistema econômico. A expansão da atividade econômica e da população nas nações e a maior necessidade de recursos hídricos destacam-se como o problema de maior probabilidade de risco para o desenvolvimento sustentável. Avaliar o volume de água que é incorporada nos produtos e serviços finais torna-se, por conseguinte, premente para a melhor gestão dos recursos hídricos de um país.

Cabe salientar, entretanto, que uma séria limitação da análise de impactos ambientais é a tendência a lidar isoladamente com cada produto ou setor (indústria), sem reconhecer a importância das relações setoriais. Embora não seja difícil conceber a existência dessas relações econômicas, no mundo real, elas tendem a ser bastante complexas, envolvendo vários grupos de produtos e de setores, diferentes formas de encadeamentos e várias hierarquias de ramificações. O modelo insumo-produto tem a capacidade de retratar essas relações em diferentes níveis de complexidade. É uma ferramenta adequada para avaliar os recursos incorporados nos produtos, usa rotinas matemáticas que permitem rastrear o uso direto, indireto e induzido de todos os recursos incorporados na produção que são destinados para o consumo final (LEONTIEF 1970).

Existem várias extensões possíveis da análise de insumo-produto, dentre as quais está a hipótese de incorporar unidades físicas ao modelo para avaliar a dimensão ambiental. Quando os fluxos monetários (vetor linha) de um setor são substituídos na matriz de transações interindustriais por unidades físicas, o modelo é conhecido como insumo-produto híbrido. A vantagem dessa abordagem, que incorpora as unidades físicas "por dentro do modelo", pressupõe que os fatores de conversão e os preços sejam diferentes entre os setores, o que torna o modelo consistente. Já, quando as unidades físicas são inseridas, por meio de um vetor linha, como parte dos fatores primários, são conhecidas como modelos insumo-produto ecológicos. A vantagem desse procedimento que incorpora as unidades físicas "por fora do modelo" permite, de maneira convencional, calculando a inversa de Leontief, converter as unidades monetárias em unidades físicas. Contudo, pressupõe que os fatores de conversão sejam os mesmos entre os setores e que os preços sejam os mesmos para os vários setores que a utilizam (MONTOYA \& FINAMORE 2019a).

Nesse contexto, o modelo insumo-produto híbrido e ecológico vem sendo utilizado para avaliar problemas relacionados ao meio ambiente, visto que recursos como terra, energia, emissões de dióxido de carbono $\left(\mathrm{CO}_{2}\right)$ e água, dentre outros, são incorporados na produção de bens e serviços. Por exemplo, BICKNELL et al. (1998) e WIEDMANN et al. (2006) utilizaram o uso da terra no modelo insumo-produto para estimar a pegada ecológica. Já, com relação ao aquecimento global, UKIDWE \& BAKSHI (2004), HILGEMBERG \& GUILHOTO (2006) e MONTOYA et al. (2019) utilizam modelos insumoproduto híbridos e ecológicos para avaliar o impacto ambiental decorrente do consumo de energia e as emissões de $\mathrm{CO} 2$. Com relação aos recursos hídricos, DIETZENBACHER \& VELAZQUEZ (2007) e ZHANG et al. (2011) utilizam o modelo insumo produto inter-regional para avaliar o comércio virtual entre regiões do mesmo país e, finalmente, ZHAO et al. (2009) e ZHI et al. (2014) utilizam o modelo insumo-produto regional para estimar a pegada hídrica 
nacional bem como o comércio de água virtual no mercado internacional.

Para a economia brasileira, com base em estimativas do uso da água, PICOLI (2016), utiliza modelo insumo-produto para avaliar o uso setorial da água verde na agricultura e de água azul na indústria, já USSAMI \& GUILHOTO (2018), VISENTIN \& GUILHOTO (2019), com o modelo insumo-produto inter-regional identificam as principais regiões e os setores que utilizam água virtual azul, bem como avaliam o padrão de exploração regional da água no Brasil. Contudo, até o momento, nenhum estudo utilizando o modelo insumoproduto foi realizado para estimar a pegada hídrica nacional. Isso até porque, pela primeira vez, no ano de 2018, a Agência Nacional de Águas do Brasil disponibilizou dados agregados, que descrevem a interação entre a água e as atividades econômicas, adequados e necessários para estimar a pegada hídrica e o comércio de água virtual do país.

\section{Metodologia}

Em geral, a pegada hídrica nacional está composta pela água doce de origem nacional e origem importada incorporada na produção dos bens e serviços finais do país. Para sua mensuração, a seguir são apresentados o modelo insumo-produto, os procedimentos metodológicos adotados nesta pesquisa e a base de dados utilizada.

\subsection{Modelo insumo-produto em unidades monetárias}

O modelo insumo-produto descreve os fluxos de bens e serviços entre os diferentes setores da economia brasileira em unidades monetárias ao longo de um ano (Tabela 1). Os fluxos intersetoriais do modelo podem ser representados da seguinte maneira. A equação (1) mostra que a soma da demanda intermediária e da demanda final é igual à demanda total do produto do setor $i$. A equação (2) mostra que o consumo intermediário mais as contribuições dos fatores de produção (Valor Adicionado) é igual à produção bruta do setor $j$. Finalmente, a equação (3) mostra a condição de equilíbrio entre a oferta e a demanda para cada um dos setores produtivos da economia.

$$
\sum_{j=1}^{n} X_{i j}+\sum_{s=1}^{n} Y_{i s}=X_{i}
$$

Demanda intermediária + Demanda final $=$ Demanda Total

$$
\sum_{i=1}^{n} X_{i j}+\sum_{r=1}^{n} Y_{r j}=X_{j}
$$

Consumo intermediário + Fatores primários (Valor adicionado)

$=$ Oferta Total

$$
X_{i}=X_{j}
$$

Demanda Total $=$ Oferta Total 
Tabela 1: Matriz insumo-produto do Brasil

\begin{tabular}{|c|c|c|c|c|}
\hline \multirow{2}{*}{ Insumo/Produto } & \multirow{2}{*}{$\begin{array}{c}\text { Consumo } \\
\text { intermediário } \\
\left(X_{i j}\right)\end{array}$} & \multicolumn{2}{|c|}{ Demanda final $\left(Y_{i s}\right)$} & \multirow{2}{*}{$\begin{array}{c}\text { Valor } \\
\text { bruto } \\
\text { da } \\
\text { produção } \\
\left(X_{i}\right)\end{array}$} \\
\hline & & $\begin{array}{l}\text { Consumo } \\
\text { doméstico }\end{array}$ & Exportações & \\
\hline Consumo intermediário & $x_{i j}$ & $f_{i}$ & $e_{i}$ & $X_{i}$ \\
\hline Importações & $m_{i j}$ & $m_{i}^{f}$ & $m_{i}^{e}$ & $m_{i}$ \\
\hline Valor adicionado & $V_{r j}$ & - & - & - \\
\hline Valor bruto dos insumos & $X_{j}$ & - & - & - \\
\hline Consumo de água doce & $w_{j}$ & - & - & - \\
\hline
\end{tabular}

Para o estudo da pegada hídrica nacional no modelo, foram deixadas em evidência as importações intermediárias e finais, equação (4), bem como adicionado, no lado dos fatores primários, um vetor linha, $w_{j}$, que contém o consumo de água doce em cada setor.

$$
m_{i}=\sum_{j=1}^{n} m_{i j}+m_{i}^{f}+m_{i}^{e}
$$

No modelo de insumo-produto, supõe-se que os coeficientes de produção sejam fixos. Desse modo, os requerimentos de insumos intermediários têm uma participação fixa em relação à produção bruta dos setores. Os coeficientes técnicos $\left(a_{i j}\right)$ representam a quantidade de insumos do setor $i$ requerida ou necessária para produzir uma unidade do produto do setor $j$. Assim:

$$
a_{i j}=\frac{x_{i j}}{X_{j}} \quad \text { ou } \quad x_{i j}=a_{i j} X_{j}
$$

Substituindo a equação (5) na equação (2), e fazendo $\sum_{s=1}^{n} Y_{i s}=Y_{i}$, obtémse o sistema de equações (6).

$$
\sum_{j=1}^{n} a_{j} X_{j}+Y_{i}=X_{i}
$$

A solução do modelo insumo-produto clássico para estudar as interdependências dos setores de uma economia pode ser expressa matricialmente pela equação (7), cuja solução é dada pela equação (8):

$$
\begin{gathered}
A X+Y=X \\
X=(I-A)^{-1} Y
\end{gathered}
$$

Os coeficientes da matriz inversa de Leontief $(I-A)^{-1}$ são chamados de requerimentos totais de produção, ou seja, requerimentos diretos e indiretos 
de produção. Eles indicam, em unidades monetárias, a produção no setor $i$ que é necessária para atender a uma unidade monetária da demanda final. Note-se que a demanda final do modelo é exógena e o elo com a produção total é construído com a matriz inversa.

\section{2 Água virtual no modelo insumo-produto}

Inicialmente, para mensurar a pegada hídrica nacional, é necessário calcular a água virtual do sistema econômico. No entanto, a água virtual, convencionalmente medida em metros cúbicos por tonelada de produção $\left(\mathrm{m}^{3} / \mathrm{t}\right)$ deve ser modificada no modelo insumo-produto como a quantidade de água incorporada por cada unidade monetária produzida para a demanda final ( $\left.\mathrm{m}^{3} / \mathrm{R} \$\right)$. A nova unidade de medida obedece aos seguintes fatos: 1) uma das principais premissas do modelo insumo-produto é que cada setor produz um único produto e todo produto utiliza os mesmos processos e tecnologia, o que significa que cada setor representa apenas um único produto na estrutura do modelo; 2) embora sejam bens físicos circulando no sistema econômico, na estrutura insumo-produto, a unidade monetária deve ser redefinida como uma unidade da água virtual - nesta pesquisa, hectômetros cúbicos de água doce por milhão de reais $\left(\mathrm{hm}^{3} / \mathrm{R} \$\right)$.

Na Tabela 1, com a inserção, de um vetor linha, do consumo setorial de água doce, o modelo insumo-produto é estendido para calcular a água virtual. Então, a matriz de coeficientes diretos da água virtual pode ser derivada como:

$$
\omega_{j}=\frac{w_{j}}{X_{j}}
$$

em que $w_{j}$ é o insumo de água doce do setor $j, X_{j}$ é o produto bruto do setor $i$, e $\omega_{j}$ é a quantidade de água consumida pelo setor $i$ para aumentar uma unidade monetária de produção no setor $j$.

$\mathrm{O}$ vetor dos coeficientes de água reescrito como uma matriz diagonal $\left(\hat{\omega}_{j}\right)$, e multiplicando pela matriz de coeficientes técnicos (A), o coeficiente direto de água virtual $\left(\alpha_{j}\right)$ será:

$$
\alpha_{j}=\sum_{i} \omega_{i} A
$$

sendo $\alpha_{j}$ a quantidade de água direta consumida pelo setor $i$ para produzir uma unidade monetária da demanda final do setor $j$.

Logo, o coeficiente total de água virtual pode ser conseguido multiplicando $\left(\hat{\omega}_{j}\right)$ pela matriz inversa de Leontief, $(I-A)^{-1}$, ou seja:

$$
\delta_{j}=\sum_{i} \omega_{i}(I-A)^{-1}
$$

em que $\delta_{j}$, conhecido como água virtual, representa a água total consumida pelo setor $i$ para gerar uma unidade monetária da demanda final no setor $j$.

Considerando que a demanda final de um produto está vinculada ao consumo direto e indireto de água, o coeficiente de água virtual indireto $\left(\gamma_{j}\right)$ é calculado subtraindo da água virtual total $\left(\delta_{j}\right)$ a água virtual direta $\left(\alpha_{j}\right)$, o que indica a necessidade de água virtual indireta do setor $i$ para produzir uma unidade monetária no setor $j$ que será destinada para a demanda final. 


\subsection{Pegada hídrica nacional no modelo insumo-produto ecológico}

Em termos gerais, a pegada hídrica nacional está composta pelos recursos hídricos de origem nacional e origem importada incorporada na produção dos bens e serviços finais do país, ou seja, a somatória da pegada hídrica interna e pegada hídrica externa (HOEKSTRA \& CHAPAGAIN 2007). Assim, torna-se necessário decompor, do consumo total de água doce do país $\left(w_{j}\right)$, a água consumida de origem nacional $\left(T_{j}\right)$, de origem importada $\left(F_{j}\right)$ e a água consumida que é exportada $\left(u_{j}\right)$ e, portanto, consumida por outros países. Desse modo, é preciso rastrear, nas diversas cadeias produtivas do sistema econômico, o consumo de água virtual nacional e importada da população de um país.

\section{Pegada hídrica interna}

A pegada hídrica interna é definida como o consumo doméstico de recursos hídricos para produzir bens e serviços finais consumidos pelos habitantes do país; em outras palavras, o consumo total de água virtual do país para satisfazer a demanda final menos a água virtual consumida para produtos de exportação.

A pegada hídrica interna pode ser apresentada como:

$$
T_{j}=\delta_{j} \times f_{j} \quad \text { ou } \quad T_{j}=\omega_{i}(I-A)^{-1} f_{j}
$$

em que $T_{j}$ representa a água utilizada para o consumo interno da demanda final, produzida no mercado interno no setor $j$, e $f_{j}$ representa, na demanda final, o consumo interno do setor $j$. Dessa forma, não considera as exportações.

Pegada hídrica externa

A pegada hídrica externa é definida como o volume anual de recursos hídricos incorporados nos bens e serviços importados pela demanda intermediária e pela demanda final do país. De outro modo, é a água virtual importada para o país menos o volume de água virtual exportada para outros países como resultado da reexportação de produtos importados.

O cálculo da pegada hídrica externa não é trivial; pelo contrário, é muito mais complexo devido às tecnologias de produção dos bens e serviços importados. Dessa maneira, as importações provenientes de outros países apresentam diferentes processos tecnológicos de produção que incorporam volumes de água virtual diferentes. Certamente, um modelo insumo-produto interregional mundial permitiria diferenciar as tecnologias de produção de cada país e, portanto, o volume de água virtual de cada produto importado. Contudo, essas informações integradas para todos os países não são disponíveis.

Para resolver o problema, assume-se a premissa, amplamente usada na literatura, de que a tecnologia de produção de um produto importado como sendo a mesma do produto doméstico, em virtude da água virtual incorporada nas importações, equivale à água que o país teria consumido se tivesse de produzir o produto importado no mercado doméstico (WIEDMANN et al. 2007, ZHAO et al. 2009).

Nesse sentido, a pegada hídrica externa ou volume de água virtual importada em cada setor da demanda intermediária e cada componente da demanda final pode ser expressa como: 


$$
F_{j}=S^{f}+S^{i n}
$$

em que $S^{f}$ é a água virtual importada diretamente para a demanda final doméstica, e $S^{\text {in }}$ representa a água virtual importada para o consumo intermediário induzido pela demanda final doméstica.

A água virtual importada diretamente para a demanda final pode ser calculada multiplicando o valor das importações incorporadas na demanda final por $\delta_{j}$ :

$$
S_{j}^{f}=\delta_{j} \times m_{j}^{f} \quad \text { ou } \quad S_{j}^{f}=\omega_{i}(I-A)^{-1} m_{j}^{f}
$$

em que $S_{j}^{f}$ denota a água virtual importada para a demanda final do setor $j$, e $m_{j}^{f}$ é o valor da importação para a demanda final do setor $j$.

Reconhecendo que apenas parte dos produtos intermediários apoiará as exportações, então, apenas uma fração da água virtual incorporada nos insumos intermediários será consumida pela demanda doméstica. A água virtual importada como uso intermediário e consumida pela demanda final doméstica $\left(S^{i n}\right)$ pode ser derivada como:

$$
S_{j}^{i n}=\left(\sum_{i} \delta_{i} \times m_{i j}\right) \times \theta_{j}
$$

em que $m_{i j}$ significa o valor de entrada intermediário da importação, $\theta_{j}$ representa um coeficiente de ajuste derivado como a proporção do resultado da demanda final menos a exportação sobre a demanda final, e $S_{j}^{i n}$ é a água virtual importada como uso intermediário do setor $j$.

Portanto, a pegada hídrica nacional (PHN) do sistema econômico como um todo é dada pela soma da pegada hídrica interna e externa, ou seja:

$$
P H N=T+S^{f}+S^{i n}
$$

Intensidade da pegada hídrica nacional

Para avaliar a distribuição do consumo de água da demanda final doméstica entre os setores do sistema econômico, o índice de intensidade da pegada hídrica $\left(\rho_{j}\right)$, proposto por ZHAO et al. (2009), é calculado como a participação da pegada hídrica nacional do setor $j$ no total da pegada hídrica nacional dividido pela participação da demanda final doméstica do setor $j$ na demanda final doméstica total, a saber:

$$
\rho_{j}=\frac{P H N_{j}}{\sum P H N_{j}} / \frac{f_{j}}{\sum f_{j}}
$$

Os resultados da pegada hídrica nacional dividida pela demanda final doméstica total mostram a situação média do consumo de água dos setores na 
demanda final doméstica. Assim, considera-se o resultado médio como um valor crítico da intensidade. Então, $\rho_{j}>1$ significa que o setor $j$ é um setor intensivo em consumo de água, $\rho_{j}<1$ significa que o setor não é intensivo no consumo de água e $\rho_{j}=1$ significa que a intensidade do setor $j$ é o mesmo que a situação média.

\subsection{Balança comercial da água virtual}

O comércio virtual de água pode ser derivado como um subproduto da contabilidade da pegada hídrica nacional. De fato, a pegada hídrica da exportação virtual de água pode ser escrita como

$$
u_{j}=\delta_{j} \times e_{j} \quad \text { ou } \quad u_{j}=\omega_{i}(I-A)^{-1} e_{j}
$$

em que $u_{j}$ é a exportação virtual de água para a demanda final do setor $j, e_{j}$ é a exportação do setor $j$.

As exportações virtuais de água não estão incluídas na contabilidade da pegada hídrica nacional. Assim, tomando como referência as importações de água virtual, a balança comercial de água virtual será:

$$
N X_{j}^{v i r t u a l}=\left(S_{j}^{f}+S_{j}^{i n}\right)-u_{j}
$$

em que $N X_{j}^{\text {virtual }}$ é o saldo da balança comercial de água virtual do setor $j$.

Note-se, na balança comercial, que as importações da água virtual têm o sinal positivo e as exportações o sinal negativo, isso porque está implícita a ideia da escassez dos recursos hídricos. Dessa forma, o alívio da crise hídrica de um país aumentará quanto mais água economizar por meio da importação de água virtual de outros territórios do planeta.

\subsection{Base de dados}

Os dados monetários utilizados nesta pesquisa foram extraídos das Matrizes de Insumo-Produto (MIP) de 2015, elaborada a partir das Contas Nacionais n. 62, fornecidas pelo Instituto Brasileiro de Geografia e Estatística (IBGE. Instituto Brasileiro de Geografia e Estatística 2018b). Os setores foram agregados em 33 setores em função dos objetivos da pesquisa. Os setores da agropecuária e indústria de transformação foram deixados em evidência em função de concentrarem o maior consumo de água do país. Para a compilação das matrizes, adotou-se o modelo de tecnologia do setor cuja hipótese central é de que a tecnologia é uma característica das atividades; assim, a tecnologia para a produção dos produtos é determinada pela atividade que os produz.

Os dados sobre a água foram extraídos das Contas Econômicas Ambientais da Água (CEAA) de 2015, elaboradas com base nas Contas Nacionais n. 60, fornecidas pelo Instituto Brasileiro de Geografia e Estatística (IBGE. Instituto Brasileiro de Geografia e Estatística 2018a), com informações das TRU Físicas construídas de acordo com o Sistema de Contas Econômico-Ambientais da Água (SEEA-Water). Desse modo, a CEAA, em sua metodologia, integra informações hidrológicas com informações econômicas de produção, consumo intermediário e consumo final. 
Cabe salientar que o conceito de pegada hídrica, associada ao consumo ou à incorporação de água na produção, está contemplado nos estoques de água doce utilizados pela CEAA para construir a MIP ambiental da água do Brasil. Assim, as informações setoriais da água utilizada ao longo do sistema econômico insumo-produto mostram a somatória da água verde, azul e cinza incorporada nos bens e serviços finais do país.

Originalmente, a CEAA apresenta uma Tabela de Recursos e Usos composta por sete fluxos hídricos e seis setores ou atividades econômicas em unidades físicas. Contudo, para esta pesquisa, as Tabelas foram desagregadas com base nas metodologias propostas por MONTOYA et al. (2014) e MONTOYA \& FINAMORE (2019b).

As informações da MIP estão a preços básicos e em milhões de reais de 2015, e as informações físicas da CEAA estão em hectômetros cúbicos $\left(\mathrm{hm}^{3}\right)$, o que corresponde a um milhão de metros cúbicos $\left(\mathrm{m}^{3}\right)$ ou um bilhão de litros de água.

\section{O consumo setorial de água e a água virtual na economia brasileira}

A interação insumo-produto dos fluxos de água com as atividades econômicas evidencia que o consumo de água no sistema econômico varia de setor para setor. A segunda coluna da Tabela 2 mostra que o consumo total de água das atividades econômicas, no Brasil, alcança o volume de $30.554 \mathrm{hm}^{3}$ ao ano. Em termos agregados, chama atenção que a produção da agropecuária responde por $77,6 \%$ ou $23.704 \mathrm{hm}^{3}$ da água consumida no país, seguido de longe pela Indústria com $12,2 \%$ ou $3.729 \mathrm{hm}^{3}$ e pelos serviços com $10,2 \%$ ou $3.120 \mathrm{hm}^{3}$.

Lembrando que a água consumida é a água que foi incorporada nos bens, a elevada concentração do consumo de água na agropecuária evidencia que as atividades que envolvem a produção de grãos e proteína animal requerem grandes volumes de água do meio ambiente. Assim, quando observados os setores vinculados ao agronegócio brasileiro - o consumo de água dos setores da agropecuária e da agroindústria -, verifica-se que, em conjunto, concentram $86,8 \%$ ou $26.508 \mathrm{hm}^{3}$ da água consumida no país. Em particular, destacam-se seis setores do agronegócio que respondem por $85,5 \%$ do consumo nacional. Tais setores são: o setor Agricultura (53,3\% ou $16.278 \mathrm{hm}^{3}$ ); o setor Pecuária $\left(21,7 \%\right.$ ou $\left.6.630 \mathrm{hm}^{3}\right)$; o setor Abate e produtos de carne $(3,9 \%$ ou 1.201 $\left.\mathrm{hm}^{3}\right)$; o setor Produção florestal $\left(2,6 \%\right.$ ou $\left.795 \mathrm{hm}^{3}\right)$; o setor Outros produtos alimentares (2,9\% ou $\left.880 \mathrm{hm}^{3}\right)$; e o setor Fabricação e refino de açúcar (1,1\% ou $322 \mathrm{hm}^{3}$ ). Cabe salientar, no entanto, que, dentre os setores de serviços, o setor Água, esgoto e gestão de resíduos também é relevante na medida em que consome $7,4 \%$ ou $2.270 \mathrm{hm}^{3}$ da água do país.

Lembrando que, no modelo insumo-produto, cada setor produz um único produto, as informações das Tabelas 2 e Gráfico 1 mostram a água virtual total para cada produto e/ou serviço final bem como a composição direta e indireta para cada setor. A água virtual direta representa a quantidade de água inicial consumida na produção de um setor para satisfazer a demanda final, e a água virtual indireta reflete o maior consumo de água nos fluxos de compras e de vendas dos setores para atender à demanda final.

De modo geral, observa-se que existem setores mais intensivos e menos intensivos na incorporação de água. Para diferenciá-los, foi estabelecido, como 
parâmetro, o conteúdo de água virtual total de um produto acima da média do país. Isso porque o aumento na demanda final de um setor relevante não somente aumentará o consumo direto de água no próprio setor, mas também forçará, nos demais setores, um aumento relativamente mais forte no consumo de água, de forma indireta na economia. 
Tabela 2: O consumo de água e a água virtual na economia brasileira - ano de 2015 , em $\mathrm{hm}^{3}$ e $\mathrm{hm}^{3} / 10^{6} \mathrm{R} \$$ ano e percentuais

\begin{tabular}{|c|c|c|c|c|c|c|c|c|}
\hline \multirow{3}{*}{ MIP ÁGUA 2015 BR - Setor } & \multirow{2}{*}{\multicolumn{2}{|c|}{$\begin{array}{c}\text { Consumo } \\
\text { de água } \\
\left(w_{j}\right)\end{array}$}} & \multicolumn{6}{|c|}{ Composição da Água virtual em $\mathrm{hm}^{3} / 10^{6} \mathrm{R} \$$} \\
\hline & & & \multicolumn{2}{|c|}{ Direto $\left(\alpha_{j}\right)$} & \multicolumn{2}{|c|}{ Indireto $\left(\gamma_{j}\right)$} & \multicolumn{2}{|c|}{ Total $\left(\delta_{j}\right)$} \\
\hline & $\mathrm{hm}^{3}$ & $\%$ & $\mathrm{hm}^{3} / \mathrm{R} \$$ & $\%$ & $\mathrm{hm}^{3} / \mathrm{R} \$$ & $\%$ & $\mathrm{hm}^{3} / \mathrm{R} \$$ & $\%$ \\
\hline 1 - Agricultura & 16.278 & 53,3 & 0,0014 & 2,5 & 0,0533 & 97,5 & 0,0547 & 100,0 \\
\hline 2 - Pecuária & 6.630 & 21,7 & 0,0036 & 6,6 & 0,0505 & 93,4 & 0,0541 & 100,0 \\
\hline 3 - Produção florestal; pesca e aquicultura & 795 & 2,6 & 0,0017 & 6,4 & 0,0253 & 93,6 & 0,0270 & 100,0 \\
\hline 4 - Indústria extrativa & 282 & 0,9 & 0,0002 & 10,4 & 0,0017 & 89,6 & 0,0019 & 100,0 \\
\hline 5 - Abate e produtos de carne, do laticínio e da pesca & 1.201 & 3,9 & 0,0178 & 63,6 & 0,0102 & 36,4 & 0,0279 & 100,0 \\
\hline 6 - Fabricação e refino de açúcar & 322 & 1,1 & 0,0278 & 75,8 & 0,0089 & 24,2 & 0,0367 & 100,0 \\
\hline 7 - Outros produtos alimentares & 880 & 2,9 & 0,0128 & 65,7 & 0,0067 & 34,3 & 0,0194 & 100,0 \\
\hline 8 - Fabricação de bebidas & 49 & 0,2 & 0,0020 & 43,3 & 0,0026 & 56,7 & 0,0045 & 100,0 \\
\hline 9 - Fabricação de produtos do fumo & 1 & 0,0 & 0,0204 & 89,7 & 0,0024 & 10,3 & 0,0228 & 100,0 \\
\hline 10 - Fabricação de produtos têxteis & 60 & 0,2 & 0,0044 & 60,4 & 0,0029 & 39,6 & 0,0074 & 100,0 \\
\hline 11 - Confecção de artefatos do vestuário e acessórios & 4 & 0,0 & 0,0009 & 34,5 & 0,0017 & 65,5 & 0,0025 & 100,0 \\
\hline 12 - Fabricação de calçados e de artefatos de couro & 4 & 0,0 & 0,0005 & 15,2 & 0,0030 & 84,8 & 0,0036 & 100,0 \\
\hline 13 - Fabricação de produtos da madeira & 17 & 0,1 & 0,0032 & 63,5 & 0,0018 & 36,5 & 0,0050 & 100,0 \\
\hline 14 - Fabricação de celulose, papel e produtos de papel & 36 & 0,1 & 0,0015 & 50,6 & 0,0015 & 49,4 & 0,0030 & 100,0 \\
\hline 15 - Fabricação de biocombustíveis & 230 & 0,8 & 0,0227 & 73,0 & 0,0084 & 27,0 & 0,0311 & 100,0 \\
\hline 16 - Refino de petróleo e coquerias & 13 & 0,0 & 0,0007 & 17,7 & 0,0032 & 82,3 & 0,0039 & 100,0 \\
\hline 17 - Fabricação de químicos, perfumaria e farmacêuticos & 101 & 0,3 & 0,0004 & 19,9 & 0,0016 & 80,1 & 0,0019 & 100,0 \\
\hline 18 - Fabricação de produtos não-metálicos & 6 & 0,0 & 0,0004 & 34,6 & 0,0008 & 65,4 & 0,0013 & 100,0 \\
\hline 19 - Produção de ferro-gusa/ferroligas, siderurgia e fundição & 119 & 0,4 & 0,0015 & 48,1 & 0,0016 & 51,9 & 0,0030 & 100,0 \\
\hline 20 - Fabricação de produtos de metal & 295 & 1,0 & 0,0005 & 10,3 & 0,0041 & 89,7 & 0,0045 & 100,0 \\
\hline
\end{tabular}

Fonte: Elaborada pelo autor com base nos dados da pesquisa. 
Tabela 2: O consumo de água e a água virtual na economia brasileira - ano de 2015 , em $\mathrm{hm}^{3} \mathrm{e} \mathrm{hm}^{3} / 10^{6} \mathrm{R} \$$ ano e percentuais (continuação)

\begin{tabular}{|c|c|c|c|c|c|c|c|c|}
\hline \multirow{3}{*}{ MIP ÁGUA 2015 BR - Setor } & \multirow{2}{*}{\multicolumn{2}{|c|}{$\begin{array}{c}\text { Consumo } \\
\text { de água } \\
\left(w_{j}\right)\end{array}$}} & \multicolumn{6}{|c|}{ Composição da Águavirtual em $\mathrm{hm}^{3} / 10^{6} \mathrm{R} \$$} \\
\hline & & & \multicolumn{2}{|c|}{ Direto $\left(\alpha_{j}\right)$} & \multicolumn{2}{|c|}{ Indireto $\left(\gamma_{j}\right)$} & \multicolumn{2}{|c|}{ Total $\left(\delta_{j}\right)$} \\
\hline & $\mathrm{hm}^{3}$ & $\%$ & $\mathrm{hm}^{3} / \mathrm{R} \$$ & $\%$ & $\mathrm{hm}^{3} / \mathrm{R} \$$ & $\%$ & $\mathrm{hm}^{3} / \mathrm{R} \$$ & $\%$ \\
\hline 21 - Fabricação de equipamentos eletrônicos e máquinas & 21 & 0,1 & 0,0002 & 22,3 & 0,0007 & 77,7 & 0,0009 & 100,0 \\
\hline 22 - Fabricação de automóveis, peças e acessórios & 23 & 0,1 & 0,0002 & 19,9 & 0,0009 & 80,1 & 0,0011 & 100,0 \\
\hline 23 - Fabricação de equipamentos de transporte e manutenção & 30 & 0,1 & 0,0002 & 22,3 & 0,0009 & 77,7 & 0,0011 & 100,0 \\
\hline 24 - Construção & 16 & 0,1 & 0,0003 & 31,7 & 0,0006 & 68,3 & 0,0009 & 100,0 \\
\hline 25 - Energia elétrica, gás natural e outras utilidades & 101 & 0,3 & 0,0001 & 15,1 & 0,0006 & 84,9 & 0,0007 & 100,0 \\
\hline 26 - Água, esgoto e gestão de resíduos & 2.270 & 7,4 & 0,0006 & 1,6 & 0,0381 & 98,4 & 0,0387 & 100,0 \\
\hline 27 - Comércio por atacado e a varejo & 104 & 0,3 & 0,0007 & 55,7 & 0,0005 & 44,3 & 0,0012 & 100,0 \\
\hline 28 - Transporte, armazenamento e correio & 25 & 0,1 & 0,0001 & 10,8 & 0,0010 & 89,2 & 0,0011 & 100,0 \\
\hline 29 - Informação e comunicação & 8 & 0,0 & 0,0001 & 17,1 & 0,0004 & 82,9 & 0,0005 & 100,0 \\
\hline 30 - Intermediação financeira, seguros e previdência & 13 & 0,0 & 0,0001 & 18,9 & 0,0003 & 81,1 & 0,0003 & 100,0 \\
\hline 31 - Atividades imobiliárias & 9 & 0,0 & 0,0000 & 33,9 & 0,0001 & 66,1 & 0,0001 & 100,0 \\
\hline 32 - Administração pública e seguridade social & 338 & 1,1 & 0,0005 & 44,3 & 0,0006 & 55,7 & 0,0012 & 100,0 \\
\hline 33 - Outras atividades de serviços & 253 & 0,8 & 0,0006 & 38,4 & 0,0009 & 61,6 & 0,0015 & 100,0 \\
\hline $\begin{array}{r}\text { TOTAL } \\
\end{array}$ & 30.554 & 100,0 & 0,1281 & 35,0 & 0,2376 & 65,0 & 0,3658 & 100,0 \\
\hline Média & & & 0,0039 & & 0,0072 & & 0,0111 & \\
\hline $\begin{array}{c}\text { Impacto multiplicador do } \\
\text { consumo de água }\end{array}$ & & & 1,0000 & & 1,85453 & & 2,8545 & \\
\hline
\end{tabular}


Figura 1: Água virtual total nos setores da economia brasileira no ano de 2015 , em $\mathrm{hm}^{3} / 10^{6} \mathrm{R} \$$ ano

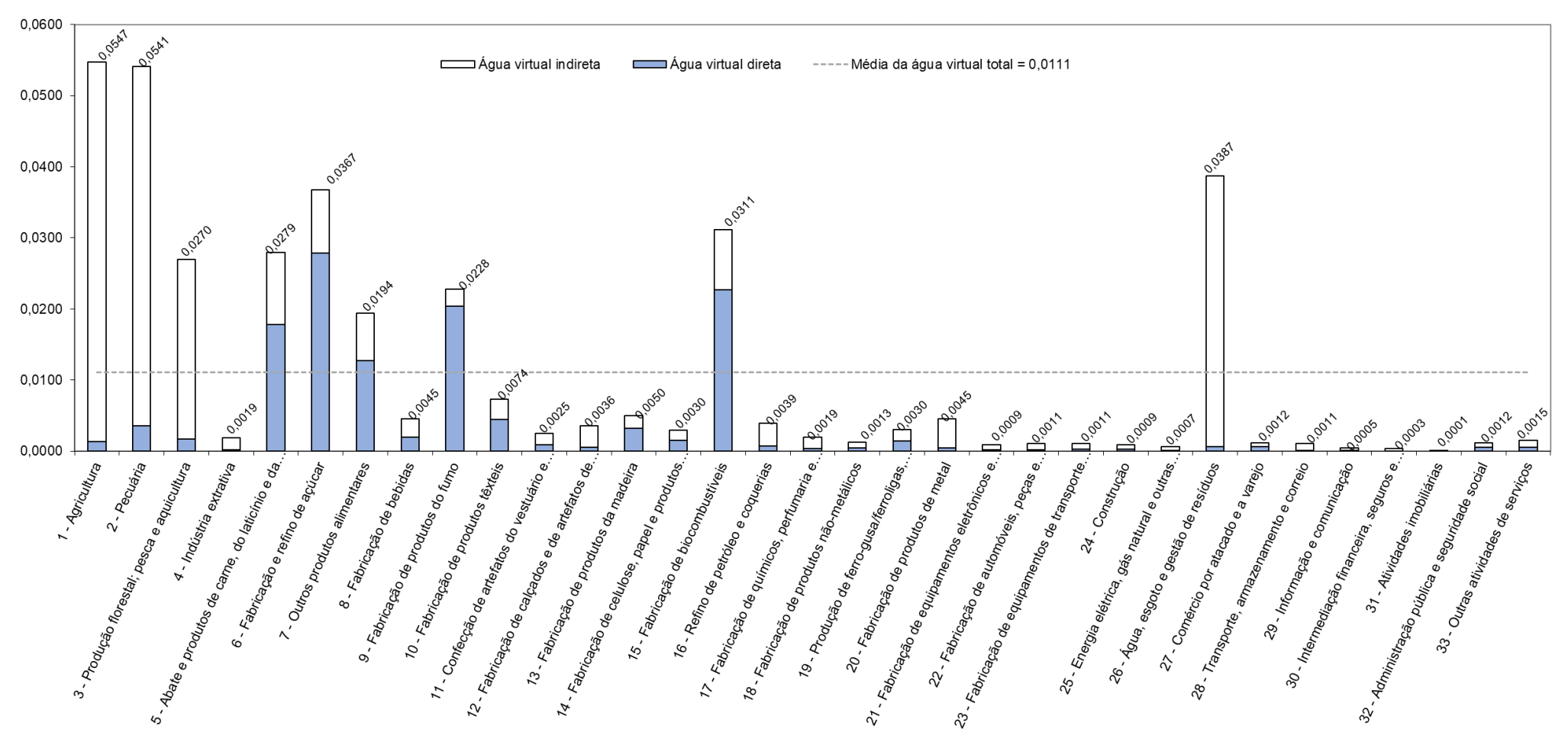

Fonte: Elaborado pelo autor com base nos dados da pesquisa. 
Considerando que a média de água virtual total do país é de $0,0111 \mathrm{hm}^{3} / \mathrm{R}$, verifica-se que nove setores exercem pressão significativa sobre o consumo de água. Dentre eles, destacam-se, na Agropecuária, o setor Agricultura (0,0547 $\left.\mathrm{hm}^{3} / \mathrm{R} \$\right)$, o setor Pecuária $\left(0,0541 \mathrm{hm}^{3} / \mathrm{R} \$\right)$ e o setor Produção florestal, pesca e aquicultura $\left(0,0270 \mathrm{hm}^{3} / \mathrm{R} \$\right)$; na Agroindústria, o setor Fabricação e refino de açúcar $\left(0,0367 \mathrm{hm}^{3} / \mathrm{R} \$\right)$, o setor Fabricação de biocombustíveis $(0,0311$ $\left.\mathrm{hm}^{3} / \mathrm{R} \$\right)$, o setor Abate e produtos de carne $\left(0,0279 \mathrm{hm}^{3} / \mathrm{R} \$\right)$, o setor Fabricação de produtos do fumo $\left(0,0228 \mathrm{hm}^{3} / \mathrm{R} \$\right)$, o setor Outros produtos alimentares $\left(0,0196 \mathrm{hm}^{3} / \mathrm{R} \$\right)$; e, nos Serviços, o setor Água, esgoto e gestão de resíduos $\left(0,0387 \mathrm{hm}^{3} / \mathrm{R} \$\right)$.

O setor Agricultura, por exemplo, que produz alimentos para o consumo nacional e internacional, mostra que o aumento de um milhão de reais na demanda final provocará um aumento de água virtual total de $0,0547 \mathrm{hm}^{3} / \mathrm{R} \$$, o que equivale a $54.700 \mathrm{~m}^{3}$ de água para ser consumida em seu processo produtivo. Logo, considerando os nove setores com maior nível de água virtual, fica evidente, em função de um eventual crescimento da demanda final, que deverá haver, simultaneamente, maiores necessidades de recursos hídricos no país. Contudo, a pressão relativa que os diversos setores da economia podem exercer sobre a necessidade de água somente pode ser estabelecida analisando em separado a relação dos efeitos diretos versus indiretos no processo produtivo, ou seja, o poder de um setor sobre o consumo de água de outros setores.

Se, na composição da água virtual total, o efeito direto, que representa o consumo inicial de água por unidade de produção, for pequeno em relação ao efeito indireto, que reflete o maior consumo de água decorrente dos fluxos de compras e vendas dos setores para atender à demanda final, o poder que exerce um setor sobre o consumo de água no sistema econômico será grande. Assim, setores com alto peso na demanda de água e que, ao mesmo tempo, apresentam uma baixa relação no consumo de água direta versus indireta, tendem a produzir as mais fortes pressões de necessidade de água (MONTOYA \& PASQUAL 2015, MONTOYA \& FINAMORE 2019a).

$\mathrm{Na}$ estrutura setorial de água virtual, a composição direto versus indireto mostra, na economia brasileira, como um todo, consumo direto de água $(35,0 \%)$, menor que o consumo indireto $(65,0 \%)$. Dessa forma, a baixa relação do efeito direto versus indireto $\left(0,1281 \mathrm{hm}^{3} / \mathrm{R} \$ \div 0,2376 \mathrm{hm}^{3} / \mathrm{R} \$=0,5391\right)$ indica, em termos relativos, que os diversos setores exercem, por meio de suas atividades produtivas, pressão sobre a necessidade de recursos hídricos do país.

Nesse contexto, a partir de uma análise mais particularizada, verifica-se que o setor Agricultura (53,3\%), o setor Pecuária $(21,7 \%)$ e o setor Água, esgoto e gestão de resíduos $(7,43 \%)$ têm um peso significativo no consumo total de água do país e apresentam as mais baixas relações de água virtual direta versus indireta, indicando que exercem forte pressão sobre o consumo de água no sistema econômico. Por exemplo, a água virtual indireta do setor Agricultura é 38,01 vezes maior do que a água virtual direta, indicando que, para cada $\mathrm{m}^{3}$ de água consumida na produção do setor, haverá a necessidade adicional de $38,01 \mathrm{~m}^{3}$ de água virtual de forma indireta.

Cabe salientar que os maiores volumes de água virtual direta do sistema econômico estão localizados no setor Fabricação e refino de açúcar $(0,0278$ $\left.\mathrm{hm}^{3} / \mathrm{R} \$\right)$, setor Fabricação de biocombustíveis $\left(0,0227 \mathrm{hm}^{3} / \mathrm{R} \$\right)$, setor Fabricação de produtos do fumo $\left(0,0204 \mathrm{hm}^{3} / \mathrm{R} \$\right)$, setor Abate e produtos de carne $\left(0,0178 \mathrm{hm}^{3} / \mathrm{R} \$\right)$ e no setor Outros produtos alimentares $\left(0,0128 \mathrm{hm}^{3} / \mathrm{R} \$\right)$. 
Contudo, se somente a água virtual direta fosse levada em consideração sem considerar a água virtual indireta, setores como Agricultura, Pecuária, Produção florestal e Água e gestão de resíduos provavelmente seriam desconsiderados pelo planejador da política de recursos hídricos. Portanto, para economizar água, não apenas se deve prestar atenção à eficiência do consumo de água no local da produção, mas também se deve observar, ao longo das cadeias produtivas, se os insumos intermediários também consomem água de maneira eficiente.

Finalmente, os resultados globais da água virtual da economia brasileira indicam que, caso se concretize o aumento de um milhão de reais na demanda final, ocorrerá, inicialmente, um aumento de água virtual direta da ordem de $0,1281 \mathrm{hm}^{3}$, seguido de um aumento de água virtual indireta de 0,2376 $\mathrm{hm}^{3}$, perfazendo um total de $0,3658 \mathrm{hm}^{3}$ de água virtual. Nota-se, portanto, que ocorrerá um efeito multiplicador de água virtual $2,8545 \mathrm{hm}^{3}$ (ou, 0,3658 $\mathrm{hm}^{3} \div 0,1281 \mathrm{hm}^{3}=2,8545 \mathrm{hm}^{3}$ ). Desse modo, um aumento equivalente a $2.854 .500 \mathrm{~m}^{3}$ de água virtual por cada milhão de reais de produção na economia brasileira.

\section{Dimensão da pegada hídrica brasileira e a balança comercial da água virtual}

A política nacional que tenha como objetivo economizar o consumo de água pode ter seus alicerces a partir de dois enfoques: um deles é identificar os setores consumidores de água virtual e incentivá-los a um padrão de consumo mais econômico; e o outro é implementar a estratégia que defenda a importação de água virtual de países com abundantes recursos hídricos, salientando sempre a relevância dos países exportadores de água virtual para o bem-estar mundial. A seguir, avaliam-se os resultados da quantificação da pegada hídrica nacional e da balança comercial tendo em vista esses enfoques.

\subsection{A pegada hídrica nacional e o consumo per-capita de água virtual}

Com base na metodologia utilizada, conforme a Tabela 3, a pegada hídrica nacional do Brasil, em 2015, atingiu o volume de $22.012 \mathrm{hm}^{3}$ de água virtual por ano, que, associada à população de 204.450 .649 habitantes, equivale a um consumo de água virtual per-capita de 107,66 m³/ano ou de 294,97 litros/dia. Em termos econômicos, a pegada hídrica nacional associada ao Produto Interno Bruto ( $\mathrm{R}$ /5.155.601milhões) evidencia no país que são consumidos 4,27 litros de água virtual para cada RS 1,00 de Valor Adicionado.

Tabela 3: A pegada hídrica nacional (PHN) e o consumo per-capita de água virtual no Brasil em 2015

\begin{tabular}{l|r|r|r|c}
\hline \multicolumn{1}{c|}{ Indicadores } & $\mathbf{h m}^{3}$ /ano & $\begin{array}{c}\mathbf{m}^{3} \text { /ano } \\
\text { per-capita }\end{array}$ & $\begin{array}{c}\text { litros/dia } \\
\text { per-capita }\end{array}$ & litros/R\$ \\
\hline Pegada hídrica nacional & 22.012 & 107,66 & 294,97 & 4,27 \\
Uso de água das famílias & 8.086 & 39,55 & 108,36 & 1,57 \\
Consumo de água das famílias & 46 & 0,22 & 0,62 & 0,01 \\
\hline
\end{tabular}

Fonte: Elaborada pelo autor com base nos dados da pesquisa e Anexo Apêndice A. 
Considerando que, dentre os componentes da demanda final, desconsiderando as exportações, as famílias concentram 85,7\% (ou, $17.061 \mathrm{hm}^{3} / 19.907$ $\left.\mathrm{hm}^{3}=0,857\right)$ do consumo doméstico do país, os resultados também indicam que as famílias consomem muito mais água incorporada nos bens e serviços finais $\left(22.012 \mathrm{hm}^{3} / \mathrm{ano}\right)$ do que a água consumida ( $\left.46 \mathrm{hm}^{3} / \mathrm{ano}\right)$ diretamente no lar. Assim, fica evidente que as informações tradicionais do uso (8.086 $\left.\mathrm{hm}^{3} / \mathrm{ano}\right)$ e do consumo $\left(46 \mathrm{hm}^{3} / \mathrm{ano}\right)$ de água das famílias subestimam a real demanda de recursos hídricos do país.

\subsection{A composição setorial da pegada hídrica nacional}

A Tabela 4 fornece a quantidade de água virtual interna e externa dos 33 setores da economia brasileira. A pegada hídrica total do Brasil, em 2015, é estimada em $22.012 \mathrm{hm}^{3} /$ ano, dos quais $19.907 \mathrm{hm}^{3} /$ ano é a pegada hídrica interna e $2.105 \mathrm{hm}^{3}$, a pegada hídrica externa. A pegada interna é responsável por $90,4 \%$ da pegada hídrica total do país, evidenciando que a água virtual interna se constitui um componente substancial para atender ao consumo final do Brasil. Embora a pegada hídrica externa represente somente 9,6\% da pegada hídrica nacional, cabe salientar que $61,1 \%$ ou $1.266 \mathrm{hm}^{3} /$ ano da água virtual importada está destinada para o consumo intermediário e 39,9\% ou $839 \mathrm{hm}^{3}$ /ano para o consumo na demanda final. Em vista disso, grande proporção da água importada é incorporada na produção das diversas cadeias produtivas do país para atender à demanda final.

A pegada hídrica total do setor Agricultura é a mais alta de todos os setores, com uma quantidade de $8.961 \mathrm{hm}^{3} /$ ano, representando $40,7 \%$ do total, seguido de longe pelo setor Pecuária, com $5.416 \mathrm{hm}^{3} /$ ano ou $24,6 \%$, e pelo setor Água, esgoto e gestão de resíduos, com $2.219 \mathrm{hm}^{3} /$ ano ou $10,1 \%$. Em conjunto, os três setores representam $75,4 \%$ da pegada hídrica nacional, o que indica uma grande concentração setorial de água virtual no país.

Em um patamar menor, os setores tais como Outros produtos alimentares (991 $\mathrm{hm}^{3} /$ ano ou 4,5\%), Abate e produtos de carne, laticínio e da pesca (980 $\mathrm{hm}^{3} /$ ano ou $\left.4,5 \%\right)$, Produção florestal, pesca e aquicultura $\left(677 \mathrm{hm}^{3} / \mathrm{ano}\right.$ ou $3,1 \%)$, Administração pública e seguridade social (385 hm $\mathrm{hm}^{3} /$ ano ou 1,8\%), Outras atividades de serviços $\left(365 \mathrm{hm}^{3} /\right.$ ano ou $\left.1,7 \%\right)$, Fabricação de produtos de metal $\left(275 \mathrm{hm}^{3} /\right.$ ano ou $\left.1,3 \%\right)$ também têm uma pegada hídrica total relativamente alta e respondem em conjunto por $16,7 \%$ da pegada hídrica nacional.

A composição da pegada hídrica total dos nove principais setores consumidores de água virtual do país é apresentada no Gráfico 2. Esses setores representam $90,8 \%$ da pegada hídrica nacional, 93,9\% da pegada hídrica interna e $61,7 \%$ da pegada hídrica externa.

Pode-se observar que a proporção de pegadas hídricas internas dos principais setores no consumo de água virtual é geralmente alta na pegada hídrica total. Por exemplo, a proporção da pegada hídrica interna da agricultura é de $94,4 \%$ ou $8.462 \mathrm{hm}^{3} / \mathrm{ano}$, da Pecuária é de $97,3 \%$ ou $5.271 \mathrm{hm}^{3} /$ ano e da Água, esgoto e gestão de resíduos é de $97,8 \%$ ou $2.170 \mathrm{hm}^{3} /$ ano.

Já no setor Outras atividades de serviços, a proporção de pegada hídrica externa é relevante, com $37,4 \%$ ou $137 \mathrm{hm}^{3} /$ ano. Considerando que esse setor contém as atividades de alojamento, de alimentação, de serviços domésticos, de educação e de saúde privada, a proporção hídrica externa sugere que a água importada está incorporada nos serviços de hotelaria, alimentos processados, bem como nos serviços pessoais de educação e de saúde. Para o setor Outros 
Tabela 4: Contabilidade ambiental da pegada hídrica na economia brasileira - ano de 2015 , em $\mathrm{hm}^{3} /$ ano e percentuais

\begin{tabular}{|c|c|c|c|c|c|c|c|c|c|c|}
\hline \multirow{3}{*}{ MIP ÁGUA 2015 BR - Setor } & \multirow{2}{*}{\multicolumn{2}{|c|}{$\begin{array}{c}\text { Pegada hídrica } \\
\text { interna }\left(T_{j}\right)\end{array}$}} & \multicolumn{4}{|c|}{ Água virtual importada } & \multirow{2}{*}{\multicolumn{2}{|c|}{$\begin{array}{c}\text { Pegada } \\
\text { hídrica } \\
\text { nacional } \\
\left(P H N_{j}\right)\end{array}$}} & \multirow{3}{*}{\begin{tabular}{|c|}
$\begin{array}{c}\text { Participação } \\
\text { setorial na } \\
\text { Pegada } \\
\text { hídrica } \\
\text { nacional }\end{array}$ \\
$\%$ \\
\end{tabular}} & \multirow{3}{*}{$\begin{array}{c}\text { Índice } \\
\text { de } \\
\text { intensidade } \\
\left(\rho_{j}\right)\end{array}$} \\
\hline & & & \multirow{2}{*}{$\begin{array}{c}\begin{array}{c}\text { Demanda } \\
\text { final interna } \\
\left(S_{j}^{f}\right)\end{array} \\
\mathrm{hm}^{3} / \mathrm{ano} \\
\end{array}$} & \multirow{2}{*}{$\begin{array}{c}\begin{array}{c}\text { Consumo } \\
\text { intermediário } \\
\text { interno }\left(S_{j}^{i n}\right)\end{array} \\
\mathrm{hm}^{3} / \mathrm{ano}\end{array}$} & \multicolumn{2}{|c|}{\begin{tabular}{|c|} 
Total Pegada \\
hídrica externa \\
$\left(F_{j}\right)$
\end{tabular}} & & & & \\
\hline & $\mathrm{hm}^{3} / \mathrm{ano}$ & $\%$ & & & h. $\mathrm{hm}^{3} / \mathrm{ano}$ & $\%$ & $\mathrm{hm}^{3} / \mathrm{ano}$ & $\%$ & & \\
\hline 1 - Agricultura & 8.462 & 94,4 & 480 & 20 & 499 & 5,6 & 8.961 & 100,0 & 40,7 & 37,54 \\
\hline 2 - Pecuária & 5.271 & 97,3 & 118 & 27 & 145 & 2,7 & 5.416 & 100,0 & 24,6 & 36,79 \\
\hline 3 - Produção florestal; pesca e aquicultura & 629 & 93,0 & 35 & 13 & 47 & 7,0 & 677 & 100,0 & 3,1 & 10,40 \\
\hline 4 - Indústria extrativa & 143 & 90,0 & 7 & 9 & 16 & 10,0 & 159 & 100,0 & 0,7 & 1,71 \\
\hline 5 - Abate e produtos de carne, do laticínio e da pesca & 913 & 93,1 & 28 & 40 & 68 & 6,9 & 980 & 100,0 & 4,5 & 1,57 \\
\hline 6 - Fabricação e refino de açúcar & 155 & 96,7 & 5 & 1 & 5 & 3,3 & 160 & 100,0 & 0,7 & 4,15 \\
\hline 7 - Outros produtos alimentares & 686 & 69,2 & 29 & 276 & 306 & 30,8 & 991 & 100,0 & 4,5 & 1,87 \\
\hline 8 - Fabricação de bebidas & 44 & 68,9 & 2 & 18 & 20 & 31,1 & 65 & 100,0 & 0,3 & 0,41 \\
\hline 9 - Fabricação de produtos do fumo & 0 & 12,9 & 0 & 2 & 3 & 87,1 & 3 & 100,0 & 0,0 & 0,10 \\
\hline 10 - Fabricação de produtos têxteis & 51 & 64,8 & 8 & 19 & 28 & 35,2 & 79 & 100,0 & 0,4 & 1,42 \\
\hline 11 - Confecção de artefatos do vestuário e acessórios & 4 & 11,8 & 1 & 26 & 26 & 88,2 & 30 & 100,0 & 0,1 & 0,15 \\
\hline 12 - Fabricação de calçados e de artefatos de couro & 3 & 26,8 & 0 & 7 & 8 & 73,2 & 10 & 100,0 & 0,0 & 0,11 \\
\hline 13 - Fabricação de produtos da madeira & 10 & 91,3 & 1 & 0 & 1 & 8,7 & 11 & 100,0 & 0,0 & 5,74 \\
\hline 14 - Fabricação de celulose, papel e produtos de papel & 20 & 75,6 & 1 & 5 & 6 & 24,4 & 26 & 100,0 & 0,1 & 0,65 \\
\hline 15 - Fabricação de biocombustíveis & 172 & 93,9 & 6 & 5 & 11 & 6,1 & 183 & 100,0 & 0,8 & 2,98 \\
\hline 16 - Refino de petróleo e coquerias & 11 & 9,9 & 0 & 98 & 98 & 90,1 & 109 & 100,0 & 0,5 & 0,33 \\
\hline 17 - Fabricação de químicos, perfumaria e farmacêuticos & 70 & 36,7 & 13 & 108 & 121 & 63,3 & 191 & 100,0 & 0,9 & 0,62 \\
\hline 18 - Fabricação de produtos não-metálicos & 5 & 18,8 & 0 & 21 & 21 & 81,2 & 26 & 100,0 & 0,1 & 0,48 \\
\hline 19 - Produçấo de ferro-gusa/ferroligas, siderurgia e fundição & 56 & 85,6 & 7 & 2 & 9 & 14,4 & 66 & 100,0 & 0,3 & 5,31 \\
\hline 20 - Fabricação de produtos de metal & 235 & 85,4 & 25 & 15 & 40 & 14,6 & 275 & 100,0 & 1,3 & 3,75 \\
\hline 21 - Fabricação de equipamentos eletrônicos e máquinas & 17 & 19,6 & 6 & 63 & 69 & 80,4 & 86 & 100,0 & 0,4 & 0,13 \\
\hline 22 - Fabricação de automóveis, peças e acessórios & 18 & 30,4 & 3 & 37 & 41 & 69,6 & 58 & 100,0 & 0,3 & 0,12 \\
\hline 23 - Fabricação de equipamentos de transporte e manutenção & 23 & 38,8 & 4 & 32 & 36 & 61,2 & 58 & 100,0 & 0,3 & 0,18 \\
\hline 24 - Construção & 16 & 23,4 & 0 & 52 & 52 & 76,6 & 67 & 100,0 & 0,3 & 0,03 \\
\hline 25 - Energia elétrica, gás natural e outras utilidades & 17 & 30,8 & 0 & 37 & 38 & 69,2 & 55 & 100,0 & 0,2 & 0,17 \\
\hline 26 - Água, esgoto e gestão de resíduos & 2.170 & 97,8 & 45 & 4 & 49 & 2,2 & 2.219 & 100,0 & 10,1 & 22,04 \\
\hline 27 - Comércio por atacado e a varejo & 94 & 55,5 & 3 & 73 & 76 & 44,5 & 170 & 100,0 & 0,8 & 0,06 \\
\hline 28 - Transporte, armazenamento e correio & 20 & 32,5 & 1 & 40 & 41 & 67,5 & 61 & 100,0 & 0,3 & 0,12 \\
\hline 29 - Informação e comunicação & 7 & 19,9 & 0 & 28 & 29 & 80,1 & 36 & 100,0 & 0,2 & 0,05 \\
\hline 30 - Intermediação financeira, seguros e previdência & 12 & 53,2 & 0 & 10 & 10 & 46,8 & 22 & 100,0 & 0,1 & 0,02 \\
\hline 31 - Atividades imobiliárias & 9 & 83,0 & 0 & 2 & 2 & 17,0 & 11 & 100,0 & 0,0 & 0,01 \\
\hline 32 - Administração pública e seguridade social & 337 & 87,3 & 0 & 48 & 49 & 12,7 & 385 & 100,0 & 1,8 & 0,08 \\
\hline 33 - Outras atividades de serviços & 228 & 62,6 & 9 & 128 & 137 & 37,4 & 365 & 100,0 & 1,7 & 0,12 \\
\hline TOTAL & 19.907 & 90,4 & 839 & 1.266 & 2.105 & 9,6 & 22.012 & $\mid 100,0$ & 100,0 & 1,00 \\
\hline
\end{tabular}

Fonte: Elaborada pelo autor com base nos dados da pesquisa. 
Figura 2: Composição da pegada hídrica dos principais setores consumidores de água virtual da economia brasileira no ano de 2015, em percentual

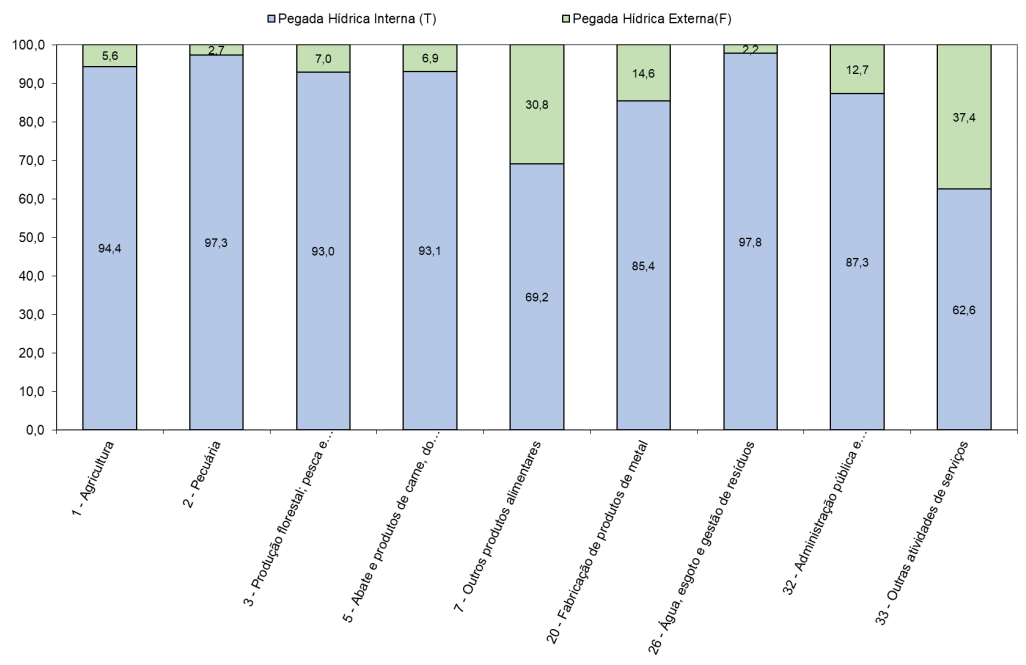

Fonte: Elaborada pelo autor com base nos dados da Tabela 4.

produtos alimentares, a pegada hídrica externa é de $30,8 \%$ ou $306 \mathrm{hm}^{3} / \mathrm{ano}$, indicando que a água virtual importada é incorporada de forma significativa na produção de alimentos processados. Essa evidência também corrobora, em parte, a elevada pegada hídrica externa do setor Outras atividades de serviços.

Embora grande parte dos setores da indústria e dos serviços não tenha relevância na participação da pegada hídrica nacional, na composição da pegada hídrica setorial, a proporção da pegada hídrica externa é extremamente relevante. Dentre eles se destacam, na Tabela 4, o setor Refino de petróleo e coquerias $(90,1 \%)$, o setor Confecção de artefatos do vestuário e acessórios $(88,2 \%)$, o setor Fabricação de produtos do fumo $(87,1)$, o setor Informação e comunicação $(80,1 \%)$, o setor Fabricação de automóveis, peças e acessórios $(69,6 \%)$ e o setor Construção $(76,6 \%)$. Assim, se o objetivo for poupar água virtual interna, esses setores deveriam ser levados em consideração para esse tipo de políticas.

\subsection{A intensidade setorial na pegada hídrica nacional}

$\mathrm{O}$ índice de intensidade da pegada hídrica $\left(\rho_{j}\right)$ permite identificar os setores que consomem mais quantidade de água virtual por unidade monetária da demanda final doméstica. Os resultados listados na Tabela 4 indicam que, dos 33 setores da economia brasileira, 14 apresentam índices maiores do que um, ou seja, setores com intensidade no consumo de água acima da média nacional. Dentre eles, três padrões distintos emergem: a) setores como a Agricultura $(37,54)$ e a Pecuária $(36,79)$, que incorporam grandes volumes de água por unidade produzida, em torno de 37 vezes mais do que a média nacional; b) setores que, em média, incorporam 9,5 vezes a média do país, tais como, os setores Água, esgoto e gestão de resíduos $(22,04)$, Produção florestal $(10,40)$, Produção de ferros, siderurgia e fundição $(5,31)$, Fabricação de produtos da madeira $(5,74)$ e Fabricação e refino de açúcar $(4,15)$; c) setores que se lo- 
calizam um pouco acima da média nacional, como os setores Fabricação de biocombustíveis $(2,98)$, Outros produtos alimentares $(1,87)$, Indústrias extrativas $(1,71)$, Abate e produtos de carne $(1,57)$ e Fabricação de produtos têxteis $(1,42)$.

No outro extremo, localizam-se os setores mais racionais no consumo de água - são os setores menos intensivos no consumo de água por unidade produzida para a demanda final. Dentre os 22 setores que compõem a indústria nacional, destacam-se 12 setores e, dentre os nove setores que compõem os serviços, destacam-se oito setores. Desse modo, em termos relativos, os setores de serviços, em função da natureza dos processos produtivos não incorporar grandes volumes de "água virtual", em sua grande maioria mostram-se mais racionais no consumo de água virtual.

\subsection{Balança comercial da água virtual na economia brasileira}

A estratégia nacional direcionada a economizar água por meio da importação de água virtual dos países com abundantes recursos hídricos pode ser considerada uma política promissora para o alívio da crise hídrica de um país. Em virtude disso, na balança comercial de água virtual, as importações são consideradas benéficas para o meio ambiente nacional, com sinal positivo, e as exportações prejudiciais apresentando, portanto, um sinal negativo. Certamente, para equilibrar os impactos positivos e negativos sobre o meio ambiente, promover a interdependência sustentável da água virtual entre as nações torna-se um objetivo importante para obter ganhos de bem-estar social mundial.

Na Tabela 5, é apresentada a balança comercial de água virtual na economia brasileira em 2015. Os resultados globais indicam que o Brasil é um exportador líquido, com um saldo exportador de $8.542 \mathrm{hm}^{3} /$ ano de água virtual. Na verdade, as exportações líquidas de água virtual da economia brasileira podem ser maiores do que os resultados alcançados. Como o cálculo da importação virtual de água é baseado na premissa de que os produtos importados possuem o mesmo volume de água virtual dos produtos produzidos no Brasil, isso pode estar superestimando a água importada na medida em que pode existir um consumo mais eficiente da água na produção dos países que se importa. Apesar disso, deve-se salientar que o volume de exportação de água virtual (10.647 $\left.\mathrm{hm}^{3} / \mathrm{ano}\right)$ em relação ao volume de importações (2.105 $\mathrm{hm}^{3}$ /ano) é cinco vezes maior.

Embora as exportações de água virtual $\left(10.647 \mathrm{hm}^{3} / \mathrm{ano}\right)$ não façam parte da contabilidade ambiental da pegada hídrica nacional $\left(22.012 \mathrm{hm}^{3} / \mathrm{ano}\right)$, elas equivalem a $48,37 \%$ da pegada hídrica do Brasil - quase a metade do consumo de água virtual do país. Frente a esse fato e considerando que o Brasil no mercado internacional detém o status de um grande fornecedor de alimentos, pode-se afirmar que o agronegócio nacional, por intermédio dos setores Agricultura (73,41\%), Pecuária (12,76\%), Abate e produtos de carne $(2,71 \%)$, Outros produtos alimentares $(1,83 \%)$, Fabricação e refino de açúcar $(1,57 \%)$ e Produção florestal (1,56\%), que em conjunto concentram 93,84\% da água virtual exportada pelo país, são os canais pelos quais a economia brasileira contribui significativamente, com recursos hídricos, para o bem-estar da população mundial.

A esse respeito, se considerar-se o consumo de água virtual per-capita do Brasil e o extrapolá-lo para a balança comercial, conforme mostra a Tabela 
Tabela 5: Contabilidade ambiental da balança comercial de água virtual na economia brasileira - ano de 2015, em $\mathrm{hm}^{3} / \mathrm{ano}$

\begin{tabular}{|c|c|c|c|c|c|c|}
\hline \multirow[t]{2}{*}{ MIP ÁGUA 2015 BR - Setor } & \multicolumn{2}{|c|}{$\begin{array}{c}\text { Importação } \\
\text { de água } \\
\text { virtual } \\
\left(S_{j}^{f}+S_{j}^{i n}\right)\end{array}$} & \multicolumn{2}{|c|}{$\begin{array}{c}\text { Exportação } \\
\text { de água } \\
\text { virtual } \\
\left(u_{j}\right)\end{array}$} & \multicolumn{2}{|c|}{$\begin{array}{c}\text { Saldo da balança } \\
\text { comercial de água } \\
\text { virtual } \\
\left(N X_{j}^{\text {virtual }}\right)\end{array}$} \\
\hline & $\mathrm{hm}^{3} / \mathrm{ano}$ & $\%$ & $\mathrm{hm}^{3} / \mathrm{ano}$ & $\%$ & $\mathrm{hm}^{3} / \mathrm{ano}$ & $\%$ \\
\hline 1 - Agricultura & 499 & 23,72 & -7.816 & 73,41 & -7.317 & 85,66 \\
\hline 2 - Pecuária & 145 & 6,87 & -1.359 & 12,76 & -1.214 & 14,22 \\
\hline 3 - Produção florestal; pesca e aquicultura & 47 & 2,26 & -166 & 1,56 & -119 & 1,39 \\
\hline 4 - Indústria extrativa & 16 & 0,75 & -139 & 1,30 & -123 & 1,44 \\
\hline 5 - Abate e produtos de carne, do laticínio e da pesca & 68 & 3,21 & -288 & 2,71 & -221 & 2,58 \\
\hline 6 - Fabricação e refino de açúcar & 5 & 0,25 & -167 & 1,57 & -162 & 1,90 \\
\hline 7 - Outros produtos alimentares & 306 & 14,52 & -194 & 1,83 & 111 & $-1,30$ \\
\hline 8 - Fabricação de bebidas & 20 & 0,96 & -4 & 0,04 & 16 & $-0,18$ \\
\hline 9 - Fabricação de produtos do fumo & 3 & 0,12 & 0 & 0,00 & 2 & $-0,03$ \\
\hline 10 - Fabricação de produtos têxteis & 28 & 1,31 & -9 & 0,08 & 19 & $-0,22$ \\
\hline 11 - Confecção de artefatos do vestuário e acessórios & 26 & 1,25 & 0 & 0,00 & 26 & $-0,31$ \\
\hline 12 - Fabricação de calçados e de artefatos de couro & 8 & 0,36 & -1 & 0,01 & 6 & $-0,07$ \\
\hline 13 - Fabricação de produtos da madeira & 1 & 0,04 & -7 & 0,07 & -6 & 0,07 \\
\hline 14 - Fabricação de celulose, papel e produtos de papel & 6 & 0,30 & -16 & 0,15 & -10 & 0,11 \\
\hline 15 - Fabricação de biocombustíveis & 11 & 0,53 & -58 & 0,55 & -47 & 0,55 \\
\hline 16 - Refino de petróleo e coquerias & 98 & 4,66 & -3 & 0,02 & 96 & $-1,12$ \\
\hline 17 - Fabricação de químicos, perfumaria e farmacêuticos & 121 & 5,74 & -30 & 0,29 & 90 & $-1,06$ \\
\hline 18 - Fabricação de produtos não-metálicos & 21 & 0,99 & -1 & 0,01 & 20 & $-0,23$ \\
\hline 19 - Produção de ferro-gusa/ferroligas, siderurgia e fundição & 9 & 0,45 & -63 & 0,59 & -54 & 0,63 \\
\hline 20 - Fabricação de produtos de metal & 40 & 1,91 & -60 & 0,56 & -20 & 0,23 \\
\hline
\end{tabular}

Fonte: Elaborada pelo autor com base nos dados da pesquisa. 
Tabela 5: Contabilidade ambiental da balança comercial de água virtual na economia brasileira - ano de 2015, em $\mathrm{hm}^{3} /$ ano (continuação)

\begin{tabular}{|c|c|c|c|c|c|c|}
\hline \multirow[t]{2}{*}{ MIP ÁGUA 2015 BR - Setor } & \multicolumn{2}{|c|}{$\begin{array}{c}\text { Importação } \\
\text { de água } \\
\text { virtual } \\
\left(S_{j}^{f}+S_{j}^{i n}\right)\end{array}$} & \multicolumn{2}{|c|}{$\begin{array}{c}\text { Exportação } \\
\text { de água } \\
\text { virtual } \\
\left(u_{j}\right)\end{array}$} & \multicolumn{2}{|c|}{$\begin{array}{c}\text { Saldo da balança } \\
\text { comercial de água } \\
\text { virtual } \\
\left(N X_{j}^{\text {virtual }}\right)\end{array}$} \\
\hline & $\mathrm{hm}^{3} / \mathrm{ano}$ & $\%$ & $\mathrm{hm}^{3} / \mathrm{ano}$ & $\%$ & $\mathrm{hm}^{3} / \mathrm{ano}$ & $\%$ \\
\hline 21 - Fabricação de equipamentos eletrônicos e máquinas & 69 & 3,27 & -4 & 0,04 & 65 & $-0,76$ \\
\hline 22 - Fabricação de automóveis, peças e acessórios & 41 & 1,93 & -6 & 0,05 & 35 & $-0,41$ \\
\hline 23 - Fabricação de equipamentos de transporte e manutenção & 36 & 1,70 & -8 & 0,07 & 28 & $-0,33$ \\
\hline 24 - Construção & 52 & 2,45 & 0 & 0,00 & 51 & $-0,60$ \\
\hline 25 - Energia elétrica, gás natural e outras utilidades & 38 & 1,80 & -2 & 0,02 & 36 & $-0,42$ \\
\hline 26 - Água, esgoto e gestão de resíduos & 49 & 2,35 & -201 & 1,89 & -151 & 1,77 \\
\hline 27 - Comércio por atacado e a varejo & 76 & 3,59 & -10 & 0,09 & 66 & $-0,77$ \\
\hline 28 - Transporte, armazenamento e correio & 41 & 1,96 & -5 & 0,04 & 37 & $-0,43$ \\
\hline 29 - Informação e comunicação & 29 & 1,36 & -1 & 0,00 & 28 & $-0,33$ \\
\hline 30 - Intermediação financeira, seguros e previdência & 10 & 0,50 & -1 & 0,01 & 9 & $-0,11$ \\
\hline 31 - Atividades imobiliárias & 2 & 0,09 & 0 & 0,00 & 2 & $-0,02$ \\
\hline 32 - Administração pública e seguridade social & 49 & 2,32 & -2 & 0,02 & 47 & $-0,55$ \\
\hline 33 - Outras atividades de serviços & 137 & 6,49 & -24 & 0,23 & 112 & $-1,31$ \\
\hline $\begin{array}{ll}\text { TOTAL } \\
\end{array}$ & 2.105 & 100,00 & -10.647 & 100,00 & -8.542 & 100,00 \\
\hline
\end{tabular}

Fonte: Elaborada pelo autor com base nos dados da pesquisa. 
6, pode-se observar que as exportações brasileiras de água virtual abastecem 98,88 milhões de habitantes com um consumo per-capita de 107,66 $\mathrm{m}^{3}$ /ano ou de 294,97 litros/dia. Nesse sentido, as exportações líquidas da balança comercial ( $\left.8.542 \mathrm{hm}^{3} / \mathrm{ano}\right)$ representam o consumo de água virtual de 79,33 milhões de habitantes, o que equivale, em 2015 a 7,7 vezes a população de Portugal (10.311.000 hab.), 1,2 vezes a população do Reino Unido (65.081.276 hab.) e quase toda a população da Alemanha (81.276.000 hab.). Certamente, quando se lembra que os produtos brasileiros são exportados, principalmente como insumos e também como produtos finais para mais de 100 países no mundo, e, em muitos casos, esses insumos são reexportados, pode-se inferir que a água virtual brasileira é distribuída para grande parte da população mundial.

Tabela 6: População equivalente ao Brasil com consumo de água virtual per-capita de $107,66 \mathrm{~m}^{3}$ /ano ou de 294,97 litros/dia - ano de 2015

\begin{tabular}{l|r|r}
\hline \multicolumn{1}{c|}{ Indicadores } & \multicolumn{1}{c|}{$\mathbf{h m}^{3} / \mathbf{a n o}$} & \multicolumn{1}{c}{ População } \\
\hline Pegada Hídrica Nacional & 22.012 & 204.450 .649 \\
Importação de água virtual & 2.105 & 19.554 .010 \\
Exportação de água virtual & -10.647 & -98.889 .787 \\
Saldo da balança comercial da água virtual & -8.542 & -79.335 .777 \\
\hline
\end{tabular}

Fonte: Elaborada pelo autor com base nos dados da pesquisa e Tabela 3.

Para uma análise mais particularizada, o Gráfico 3 mostra o saldo da balança comercial de água virtual de cada setor no Brasil em 2015. Os setores acima da linha horizontal são os importadores líquidos de água virtual, enquanto os que estão abaixo da linha são exportadores líquidos.

Observa-se que, dos 33 setores da economia brasileira, 21 apresentam saldo de importação líquida, que, em conjunto, somam $902 \mathrm{hm}^{3} /$ ano de água virtual; e 12 setores apresentam saldo de exportações líquidas, alcançando, em conjunto, o volume de $9.443 \mathrm{hm}^{3}$ /ano de água virtual. Assim sendo, o saldo exportador extremamente elevado representa 10,5 vezes o saldo importador. Dentre os setores com saldo de exportações líquidas, destacam-se principalmente o setor Agricultura, com $7.317 \mathrm{hm}^{3} /$ ano, o setor Pecuária, com 1.214 $\mathrm{hm}^{3} /$ ano, e o setor Abate e produtos de carne, com $221 \mathrm{hm}^{3} /$ ano. Já, dentre os setores com saldo líquido de importações, destacam-se o setor Outros produtos alimentares, com $111 \mathrm{hm}^{3} / \mathrm{ano}$, e o setor Outras atividades de serviços, com $106 \mathrm{hm}^{3} /$ ano.

Nesse panorama e considerando que as Nações Unidas (ONU) estimam até 2025 que cerca de dois terços da população mundial sofrerão com a escassez de água, o consumo dos recursos hídricos, além de ser uma questão ambiental, nas últimas décadas, passou a ser um problema econômico, já que o consumo de água deve ser otimizado objetivando maiores benefícios para a população. Embora os recursos hídricos sejam escassos, atualmente ninguém paga pela água virtual incorporada nos produtos, pois não existe um mercado formal de água virtual. 
Figura 3: Saldo líquido setorial no comércio de água virtual da economia brasileira no ano de 2015, em $\mathrm{hm}^{3}$

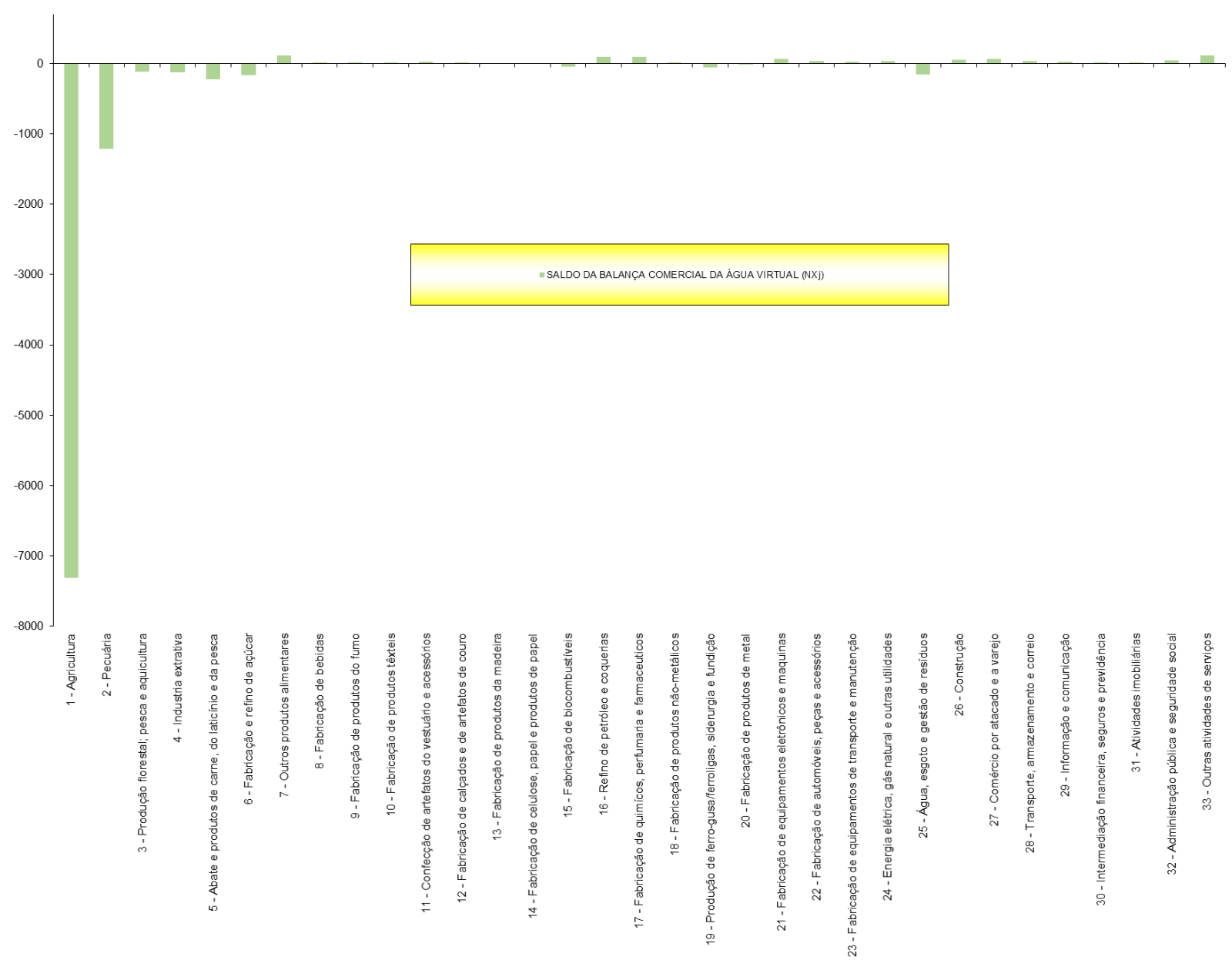


Em termos econômicos, para que o consumo de água seja sustentável, a escassez e a poluição precisam ser incluídas no preço dos bens e serviços por meio da remuneração da água virtual. Isso certamente poderá criar um incentivo para consumir de forma mais racional e poluir menos a água no planeta. Assim, o comércio de água virtual, com respeito ao meio ambiente, poderá criar grandes oportunidades de negócios ao Brasil por ser um líquido exportador de água virtual.

\section{Considerações finais}

Este artigo teve como objetivo mensurar a pegada hídrica brasileira, bem como avaliar no mercado internacional o saldo da balança comercial de água virtual. Para isso, foi construído um modelo insumo-produto ecológico que incorpora o consumo setorial de água para o ano de 2015.

Com relação ao consumo setorial de água, verificou-se que existe, no país, concentração no consumo, na medida em que a agropecuária responde por $77,6 \%$, a Indústria por $12,2 \%$ e os Serviços por $10,2 \%$.

A quantidade total de água virtual consumida em cada setor para produzir uma unidade monetária destinada para a demanda final destacou, principalmente, os setores da agropecuária e da agroindústria como aqueles que incorporam grandes volumes de água por unidade produzida no sistema econômico. O mais emblemático é o setor Agricultura, que produz alimentos para o consumo nacional e internacional, mostrando que o aumento de um milhão de reais na demanda final provocará de forma direta e indireta um aumento de água virtual total de $54,700 \mathrm{~m}^{3}$ para ser consumida em seu processo produtivo.

$\mathrm{Na}$ estrutura setorial de água virtual total, a composição direto versus indireto mostra, na economia brasileira, que os maiores volumes de água virtual direta estão localizados, dentre outros, no setor Fabricação e refino de açúcar, setor Fabricação de biocombustíveis e setor Fabricação de produtos do fumo. Contudo, se somente o consumo direto fosse levado em consideração sem levar em conta o consumo de água virtual indireta, setores como Agricultura, Pecuária, Produção florestal e Água, esgoto e gestão de resíduos provavelmente seriam desconsiderados pelo planejador da política de recursos hídricos. Para economizar água, torna-se fundamental, portanto, prestar atenção à eficiência do consumo de água ao longo das cadeias produtivas.

Quanto à pegada hídrica nacional, verificou-se que o Brasil consome 22.012 $\mathrm{hm}^{3}$ de água virtual por ano, o que equivale a um consumo per-capita de $107,66 \mathrm{~m}^{3}$ /ano ou de 294,97 litros/dia. Constatou-se também que o sistema produtivo do país depende substancialmente da pegada interna responsável por $90,4 \%$ da pegada hídrica nacional. Embora a pegada hídrica externa represente somente $9,6 \%$, ficou evidente que $60,1 \%$ da água virtual importada está destinada, na forma de insumos, para o consumo intermediário das diversas cadeias produtivas do país.

Em nível setorial, verificou-se elevada concentração de água virtual na produção da Agricultura $(40,7 \%)$ e da Pecuária $(24,6 \%)$ já que, em conjunto, respondem por $65,3 \%$ da pegada hídrica nacional. Em um patamar menor, apresentam destaque as atividades de água e gestão de resíduos, bem como o da agroindústria de alimentos. Verificou-se também que os setores da agropecuá- 
ria e agroindústria, em geral, e o setor água e gestão de resíduos, em particular, apresentam os maiores índices de intensidade no consumo de água virtual.

Com relação à balança comercial de água virtual, verificou-se que o Brasil é um exportador líquido, com um saldo de $8.542 \mathrm{hm}^{3} /$ ano de água virtual. Embora as exportações de água virtual $\left(10.647 \mathrm{hm}^{3} / \mathrm{ano}\right)$ não façam parte da contabilidade ambiental da pegada hídrica nacional $\left(22.012 \mathrm{hm}^{3} / \mathrm{ano}\right)$, verificouse que elas equivalem quase a metade do consumo de água virtual do país, e os setores do agronegócio são os principais canais pelos quais o país contribui significativamente, com recursos hídricos, para o bem-estar social da população mundial.

A respeito, verificou-se que o saldo líquido exportador da balança comercial de água virtual é capaz de abastecer 79,33 milhões de habitantes com um consumo per-capita de $107,66 \mathrm{~m}^{3} /$ ano. Esses habitantes equivalem a 7,7 vezes a população de Portugal, 1,2 vezes a população do Reino Unido e quase toda a população da Alemanha.

Por fim, considerando que a população mundial sofre com a escassez de água, o consumo dos recursos hídricos, além de ser uma questão ambiental, passou a ser um problema econômico. Assim, para que o consumo de água seja sustentável, a escassez e a poluição precisam ser incluídas no preço dos bens e serviços por meio da remuneração da água virtual. Isso certamente poderá criar um incentivo para consumir de forma mais racional e sustentável a água no planeta. O comércio de água virtual, com respeito ao meio ambiente, poderá criar grandes oportunidades de negócios ao Brasil por ter abundantes recursos hídricos e ser um líquido exportador de água virtual.

\section{Referências Bibliográficas}

ALLAN, J. A. (1998). Virtual water: a strategic resource. Ground Water, v. 36, n. 4 , p. $545,1998$.

ANA. Agência Nacional de Águas (2018). Contas econômicas ambientais da água no Brasil 2013-2015. Brasília: Agência Nacional de Águas, Instituto Brasileiro de Geografia e Estatística, Secretaria de Recursos Hídricos e Qualidade Ambiental, 2018.

BICKNELL, K. B., BALL, R. J., CULLEN, R. \& BIGSBY, H. R. (1998). New methodology for the ecological footprint with an application to the New $\mathrm{Ze}$ aland economy. Ecological Economics, v. 27, n. 2, p. 149-160, 1998.

BLENINGER, T. \& KOTSUKA, L. K. (2015). Conceitos de água virtual e pegada hídrica: estudo de caso da soja e óleo de soja no Brasil. Revista Recursos Hídricos [online], v. 36, n. 1, p. 15-24, mai. 2015.

CHAPAGAIN, A. K. \& HOEKSTRA, A. Y. (2007). The water footprint of coffee and tea consumption in the Netherlands. Ecological Economics, v. 64, p. 109-118, 2007.

DIETZENBACHER, E. \& VELAZQUEZ, E. (2007). Analyzing Andalusian virtual water trade in an input-output framework. Regional Studies, v. 41, n. 2, p. 185-196, 2007. DOI: https://doi.org/10.1080/00343400600929077.

EMBRAPA. Empresa Brasileira de Pesquisa Agropecuária (2016). Notícias, 2016. Disponível em https: / / www. embrapa.br/busca-de-noticias/-/noticia/ 
12990229/brasil-esta-entre-os-paises-com-maior-area-irrigada-do-mundo. Acesso em: 19 fev. 2019.

GLEICK, P. H. (2000). The changing water paradigm: A look at twenty-first century water resources development. Water International, v. 25, p. 127-138, 2000.

HilgemBERG, E. M. \& GUILHOTO, J. J. M. (2006). Uso de combustíveis e emissões de $\mathrm{CO}_{2}$ no Brasil: um modelo inter-regional de insumo-produto. Nova Economia, Belo Horizonte, v. 16, n. 1, p. 49-99, abr. 2006.

HOEKSTRA, A. Y. (2009). Human appropriation of natural capital: A comparison of ecological footprint and water footprint analysis. Ecological Economics, v. 68, p. 1963-1974, 2009.

HOEKSTRA, A. Y. \& CHAPAGAIN, A. K. (2007). Water footprints of nations: water use by people as a function of their consumption pattern. Water Resources Management, n. 21, p. 35-48, 2007.

HOEKSTRA, A. Y., CHAPAGAiN, A. K., ALDAYA, M. M. \& MEKONNEN, M. M. (2011). The Water Footprint Assessment Manual: Setting the Global Standard. London: Earthscan, 2011.

HOEKSTRA, A. Y. \& HUNG, P. Q. (2002). Virtual water trade: a quantification of virtual water flows between nations in relation to international crop trade. Value of Water Research Report Series, n. 11. Delft, The Netherlands: UNESCO-IHE, 2002.

IBGE. Instituto Brasileiro de Geografia e Estatística (2018a). Contas Nacionais n. 60. Contas Econômicas Ambientais da Água de 2013-2015- CEAA. Rio de Janeiro: IBGE, 2018a.

IBGE. Instituto Brasileiro de Geografia e Estatística (2018b). Contas Nacionais n. 62. Matriz de Insumo Produto 2015. Rio de Janeiro: IBGE, 2018b.

LEONTIEF, W. (1970). Environmental repercussions and the economic structure: An input-output approach. The Review of Economics and Statistics, v. 52, n. 3, p. 262-271, 1970.

MONTOYA, M. A., BERTUSSI, L, A., LOPES, R. L. \& FINAMORE, E. F. (2019). Uma nota sobre consumo energético, emissões, renda e emprego na cadeia de soja no Brasil. Revista Brasileira de Economia, Rio de Janeiro, v. 73, n. 3, p. 345-369, jul./set. 2019. DOI: ht tps: // doi .org/10.5935/0034-7140.20190016.

MONTOYA, M. A. \& FINAMORE, E. F. A. (2019a). As relações intersetoriais dos recursos hídricos na economia brasileira. Texto para discussão, n. 11, 2019a. Disponível em https://www.upf.br/_uploads/Conteudo/cepeac/ textos-discussao/11-2019.pdf Acesso em: 8 set. 2019.

MONTOYA, M. A. \& FINAMORE, E. F. A. (2019b). Os recursos hídricos no agronegócio brasileiro: uma análise insumo-produto do uso, consumo, eficiência e intensidade. Texto para discussão, n. 10, 2019b. Disponível em https://www.upf.br/_uploads/Conteudo/cepeac/textos-discussao/ 10-2019. pdf. Acesso em: 10 nov. 2019. 
MONTOYA, M. A., LOPES, R. L. \& GUILHOTO, J. J. M. (2014). Desagregação setorial do balanço energético nacional a partir dos dados da Matriz InsumoProduto: uma avaliação metodológica. Economia Aplicada, Ribeirão Preto, v. 18, n. 3, p. 379-419. DOI: https://doi .org/10.1590/1413-8050/ea463.

MONTOYA, M. A. \& PASQUAL, C. A. (2015). O uso setorial de energia renovável versus não renovável e as emissões de $\mathrm{CO}_{2}$ na economia brasileira: um modelo insumo-produto híbrido para 53 setores. Pesquisa e Planejamento Econômico-PPE, Rio de Janeiro, v. 45, n. 2, p. 288-335, ago. 2015.

OEL, P. R. \& HOEKSTRA, A. Y. (2012). Towards quantification of the water footprint of paper: A first estimate of its consumptive component. Water Resource Management, v. 11, p. 9942-9949, 2012.

PENA, R. F. A. (2018). Escassez de água no Brasil. Brasil Escola, 2018. Disponível em https://brasilescola.uol.com.br/geografia/ escassez-agua-no-brasil.htm. Acesso em: 24 out. 2018.

PICOLI, I. T. (2016), PhD thesis. Pegada hídrica da economia brasileira: uma análise de insumo-produto. 2016. 129 f. Dissertação (Mestrado em Desenvolvimento Econômico) - Instituto de Economia da Universidade Estadual de Campinas, Campinas, 2016.

RODRIGUEZ, C. I., GALARRETA, V. A. R. \& KRUSE, E. E. (2014). Analysis of water footprint of potato production in the pampean region of Argentina. nalysis of water footprint of potato production in the pampean region of Argentina, v. 90, p. 91-96, 2014. DOI: ht tps: // doi .org/10.1016/ j . jclepro.2014.11. 075.

SU, M. H., HUANG, C. H., LI, W. Y., TSO, C. T. \& LUR, H. S. (2015). Water footprint analysis of bioethanol energy crops in Taiwan. Journal of Cleaner Production, v. 88, p. 132-e138, 2015. DOI: https://doi.org/10.1016/j . jclepro. 2014.06.020.

UKIDWE, N. U. \& BAKSHI, B. R. (2004). Thermodynamic accounting of ecosystem contribution to economic sectors with application to 1992 U.S. economy. Environmental Science E Technology, v. 38, n. 18, p. 4810-4827, 2004. DOI: https://doi .org/10.1021/es035367t.

USSAMI, K. A. \& GUILHOTO, J. J. M. (2018). Economic and water dependence among regions: The case of Alto Tiete, São Paulo State, Brazil. EconomiA, v. 19, n. 3, p. 350-376, 2018. DOI: https://doi.org/10.1016/ j.econ. 2018.06.001.

VISENTIN, J. C. \& GUILHOTO, J. J. M. (2019). The Role of Interregional Trade in Virtual Water on the Blue Water Footprint and the Water Exploitation Index in Brazil. The Review of Regional Studies, v. 49, n. 2, p. 299-322, 2019.

WICHELNS, D. (2010). Virtual water: a helpful perspective, but not a sufficient policy criterion. Water Resource Management, n. 24, p. 2203-2219, 2010.

WIEDMANN, T., LENZEN, M., TURNER, K. \& BARRETT, J. (2007). Examining the global environmental impact of regional consumption activities Part 2: review of input-output models for the assessment of environmental 
impacts embodied in trade. Ecological Economics, v. 61, p. 15-26, 2007. DOI: https://doi.org/10.1016/j . ecolecon.2006.12.003.

WIEDMANN, T., MINX, J., BARRETT, J. \& WACKERNAGEL, M. (2006). Allocating ecological footprints to final consumption categories with inputoutput analysis. Ecological Economics, v. 56, p. 28-48, 2006. DOI: https:// doi .org/10.1016/ j . ecolecon.2005.05.012.

ZHANG, Z., YANG, H. \& SHI, M. (2011). Analyses of water footprint of Beijing in an interregional input-output framework. Ecological Economics, v. 70, p. 2494-2502, 2011. DOI: https://doi .org/10.1016/ j. ecolecon.2011.08. 011.

ZHAO, X., B, C. \& F, Y. Z. (2009). National water footprint in an input-output framework: a case study of China 2002. Ecological Modelling, v. 220, p. 245253, 2009. DOI: https://doi .org/10.1016/ j . ecolmodel.2008.09.016.

ZHI, Y., YANG, Z. F. \& YIN, X. A. (2014). Decomposition analysis of water footprint changes in a water-limited river basin: a case study of the Haihe River basin, China. Hydrology and Earth System Sciences, v. 18, p. 1549-1559, 2014. DOI: $10.5194 /$ hess-18-1549-2014.

\section{Apêndice A}


Tabela A.1: Os fluxos relativos do uso e consumo da água na economia brasileira - 2015 ( $\mathrm{hm}^{3} /$ ano e percentuais)

\begin{tabular}{|c|c|c|c|c|c|c|c|c|c|c|}
\hline \multirow[b]{2}{*}{ Fluxos } & \multirow[b]{2}{*}{$\begin{array}{c}\text { Recursos e } \\
\text { usos }\left(\mathrm{hm}^{3} / \text { ano }\right)\end{array}$} & \multicolumn{7}{|c|}{ Atividades econômicas } & \multirow[b]{2}{*}{$\begin{array}{c}\text { Famílias } \\
\text { (8) }\end{array}$} & \multirow[b]{2}{*}{$\begin{array}{c}\text { Total } \\
(9)\end{array}$} \\
\hline & & $\begin{array}{c}\text { Agro. } \\
\text { (1) }\end{array}$ & $\begin{array}{l}\text { Ind. Extrativa } \\
(2)\end{array}$ & $\begin{array}{c}\text { Ind. Trans. } \\
\text { e construção } \\
(3)\end{array}$ & $\begin{array}{c}\text { Eletricidade } \\
\text { e gás } \\
(4)\end{array}$ & $\begin{array}{l}\text { Água e } \\
\text { esgoto } \\
\text { (5) }\end{array}$ & $\begin{array}{c}\text { Demais } \\
\text { atividades } \\
(6)\end{array}$ & \begin{tabular}{|c|} 
Total das \\
atividades \\
$(7)$
\end{tabular} & & \\
\hline $\begin{array}{l}\text { Do meio ambi- } \\
\text { ente }\end{array}$ & 1. Retirada total. & 32.505 & 1.037 & 6.112 & 3.114 .293 & 47.085 & & 3.201 .032 & 699 & 3.201 .731 \\
\hline \multirow[t]{2}{*}{$\begin{array}{l}\text { Dentro da econo- } \\
\text { mia }\end{array}$} & $\begin{array}{l}\text { 2. Uso de água } \\
\text { proveniente de } \\
\text { outras atividades } \\
\text { econômicas. }\end{array}$ & 1.138 & 7 & 277 & 7 & 6.914 & 2.045 & 10.389 & 7.387 & 17.775 \\
\hline & $\begin{array}{l}\text { 3. Uso total da } \\
\text { água }(1+2) .\end{array}$ & 33.643 & 1.044 & 6.389 & 3.114 .300 & 53.999 & 2.045 & 3.211 .421 & 8.086 & 3.219 .507 \\
\hline $\begin{array}{l}\text { Dentro da econo- } \\
\text { mia }\end{array}$ & $\begin{array}{l}\text { 4. Suprimento } \\
\text { para outras ati- } \\
\text { vidades econômi- } \\
\text { cas. }\end{array}$ & 0 & 4 & 171 & 4 & 10.862 & 1.298 & 12.340 & 5.436 & 17.776 \\
\hline $\begin{array}{l}\text { Retorno para o } \\
\text { meio ambiente }\end{array}$ & 5. Retorno total. & 9.938 & 758 & 2.768 & 3.114 .195 & 40.868 & & 3.168 .527 & 2.604 & 3.171 .131 \\
\hline \multirow[t]{3}{*}{$\begin{array}{l}\text { Retorno para o } \\
\text { meio ambiente }\end{array}$} & $\begin{array}{l}\text { 6. Total fornecido } \\
(4+5) .\end{array}$ & 9.939 & 762 & 2.939 & 3.114 .199 & 51.730 & 1.298 & 3.180 .867 & 8.040 & 3.188 .907 \\
\hline & $\begin{array}{l}\text { 7. Consumo total } \\
(3-6) \text {. }\end{array}$ & 23.704 & 282 & 3.450 & 101 & 2.270 & 748 & 30.554 & 46 & 30.600 \\
\hline & $\begin{array}{l}\text { 8. Participação no } \\
\text { Uso total das ati- } \\
\text { vidades ( } 3 / \text { coluna } \\
\text { 8). } \\
\text { 9. Participação } \\
\text { no Consumo to- } \\
\text { tal das atividades } \\
\text { (7/coluna } 8) \text {. }\end{array}$ & $\begin{array}{r}1,05 \% \\
77,58 \%\end{array}$ & $0,92 \%$ & $11,29 \%$ & $96,98 \%$ & $7,43 \%$ & $2,45 \%$ & $100,00 \%$ & $0,15 \%$ & $100,00 \%$ \\
\hline
\end{tabular}


